\title{
Elucidating the role of clay-modifier on the properties of silica- and silica/nanoclay-reinforced natural rubber tire compounds
}

\author{
S. Sattayanurak ${ }^{1,2}$, K. Sahakaro ${ }^{1}$, W. Kaewsakul ${ }^{2}$, W. K. Dierkes ${ }^{2}$, L. A. E. M. Reuvekamp ${ }^{2,3}$, \\ A. Blume ${ }^{2}$, J. W. M. Noordermeer ${ }^{2}$ \\ ${ }^{1}$ Department of Rubber Technology and Polymer Science, Faculty of Science and Technology, Prince of Songkla \\ University, 94000 Pattani Campus, Thailand \\ ${ }^{2}$ Elastomer Technology and Engineering, Department of Mechanics of Solids, Surfaces and Systems, Faculty of \\ Engineering Technology, University of Twente, P.O.Box 217, 7500AE Enschede, The Netherlands \\ ${ }^{3}$ Apollo Tyres Global R\&D B.V., Colosseum 2, 7521PT Enschede, The Netherlands
}

Received 17 November 2020; accepted in revised form 28 January 2021

\begin{abstract}
Organoclay (OC) is one of the potential secondary fillers to be applied in silica-reinforced rubber compounds for tire applications. Commercial OC contains a large proportion of surface modifier, i.e., dimethyl dihydrogenated tallow ammonium chloride (2HT) type, that has an influence on the compound properties. To elucidate the effect of $2 \mathrm{HT}$ on the properties of silica-Natural Rubber (NR) compounds, a silica-only system, silica/OC, and silica/montmorillonite (MMT)/2HT added in situ during mixing, were comparatively studied. Irrespective in which form $2 \mathrm{HT}$ is added, it has potential to further enhance the performance of silica-NR compounds. Incorporation of 2HT suppresses filler flocculation and improves processability. Overall, the silica-only filled compound shows better mechanical properties than the silica/clay dual filler systems. The use of a small amount (2.4-4.7 phr) of $2 \mathrm{HT}$ improves $300 \%$ modulus, tear strength and abrasion resistance. The silica/OC gives better mechanical properties than the silica/MMT/2HT. With the optimum content of $2 \mathrm{HT}$, a higher $\tan \delta$ at $-20^{\circ} \mathrm{C}$ and lower $\tan \delta$ at $60^{\circ} \mathrm{C}$ can be achieved, all showing the beneficial potential of utilization of the modifying agent to improve wet traction and rolling resistance of silica-based tire tread compounds.
\end{abstract}

Keywords: reinforcement, rubber, nanoclay, surface modifying agent, silica

\section{Introduction}

Tires with better energy saving, safety and durability are required to meet more stringent customer's requirement as well as new legislations/regulations. Reinforcement materials such as carbon black (CB) and silica are added to rubber compounds to improve some basic requirement in properties such as modulus, hardness, tensile strength and tear resistance. Moreover, key tire tread performances which include wet traction, rolling resistance and wear need to be optimized. Tires generally contain $30-35 \%$ of $\mathrm{CB}$ of several grades that are used for different parts [1]. After 1992 when Michelin first introduced silica for passenger car tire tread compounds [2] showing that it could reduce rolling resistance and enhance wet grip, silica-reinforced tire treads became the subject of investigations worldwide in order to produce tires with better energy savings and driving safety [3]. However, mixing of silica into tire rubbers faces several difficulties such as poor dispersion and distribution in the rubber matrix, incompatibility with non-polar rubbers and poor fillerrubber interaction. To overcome those problems, silane coupling agents that contain sulfur in the structure such as bis-(3-triethoxysilylpropyl)tetrasulfide 
(TESPT) are generally used in silica-reinforced rubber compounds to promote silica-rubber interaction, better silica dispersion and also to suppress accelerator adsorption on the silica surface. As TESPT has some drawbacks like short scorch time and premature crosslinking in a rubber compound [4], so a silane coupling agent with lower sulfur rank like bis(3-triethoxysilylpropyl)disulfide (TESPD) can be applied to provide better scorch safety. By mixing rubber with silica-TESPT or -TESPD silane coupling agents, the silanization reaction takes place during mixing and the extent of reaction is mainly governed by the mixing temperature [5-10]. The silanization reaction between silica and the silane coupling agent increases with increasing mixing discharge or dump temperature, as indicated by a reduction of filler-filler interactions, and an increase of filler-elastomer interactions. The optimum dump temperature for silica-reinforced NR compounds is in the range of $135-150^{\circ} \mathrm{C}$ [9]. The extent of the silanization has a dramatic effect on the resulting compound properties $[6,7,9]$. The optimum mixing dump temperature for hybrid fillers of silica/OC and silica/CB (N134) in natural rubber (NR) compounds at $45 / 10 \mathrm{phr}$ was recently reported [11]. Based on basic mathematical models and response surface methodology applied for styrene-butadiene rubber (SBR)/organoclay nanocomposites, the predicted and experimental data agreed that by increasing temperature and mixing time a better organoclay dispersion and tensile property was achieved [12]. Additionally, compatibilization between silica and NR by means of epoxidized natural rubber (ENR) as compatibilizer has been investigated. The results showed a reduction in Payne effect, enhancement of fillerrubber interaction and better silica dispersion by adding either ENR [13] or epoxidized low molecular weight natural rubber (ELMWNR) [14] as compatibilizer when compared to the compound without ENR. Similar results were reported for the effect of silane-grafted NR as compatibilizer in silica-filled rubber tire compounds [15].

Nowadays, nanofillers attract a lot of interests for material development including rubber compounds for high performance products. This is due to their potential to improve compound properties at lower content used (usually less than $10 \mathrm{phr}$ ) as compared to conventional reinforcing fillers like $\mathrm{CB}$ and silica (usually higher than $30 \mathrm{phr}$ ) [16-18]. The large specific surface area of nanofillers provides larger contact spots between polymer and filler. If the interfacial interaction between nanofiller and polymer is strong enough, an efficient stress transfer from the matrix to filler will be obtained. Nanoclay has been widely studied in rubber compounds because it has the potential to offer a very high degree of reinforcement, high thermal stability, improved impermeability to gases and liquids, good optical clarity, and enhanced flame retardancy [19]. The commonly used nanoclay layered silicates are 2:1 phyllosilicates including hectorite, saponite, montmorillonite, and synthetic mica. Montmorillonite (MMT) has been widely investigated due to its low cost, abundance in nature, high surface area, high aspect ratio, and good surface reactivity [19]. However, original MMT appears in the form of stacks of clay platelets with hydrophilic silicate surfaces. So, it is incompatible with tire rubbers like NR, styrene butadiene rubber (SBR), butadiene rubber (BR). To enhance the dispersion and promote intercalation/exfoliation of clay in the rubber matrix, cation exchange with ammonium salts or phosphonium salts is the most commonly used technique to alter the hydrophilic to hydrophobic surface. The obtained material is called organically modified clay or shortly organoclay (OC) [20]. The OC may be dispersed in single platelets or small silicate stacks with a high aspect ratio of 50-1000 [21]. The use of $\mathrm{OC}$ as a single filler in elastomers shows an improvement in mechanical properties, thermal stability, wear resistance and gas impermeability. A study on microstructural evolution of rubber/clay nanocomposites during the vulcanization process showed that the intercalated structure of OC changed throughout the whole curing process, and the spatial distribution of OC was much better in a polar rubber matrix than in a non-polar rubber matrix [22].

The use of nanofillers alone cannot meet the requirements for most of high performance rubber products, especially for tire applications, that require a certain modulus and hardness level. A combination of nanofiller with conventional fillers either $\mathrm{CB}$ or silica is therefore an alternative. The idea is to obtain a synergistic reinforcing effect from each filler type. Hybrid fillers of silica with different types of fillers have been investigated such as silica/CB [23-28], silica/kaolin or China clay [29], silica/MMT [30, 31], silica/organomodified kaolin [32] and silica/OC [11, $33,34]$. The utilization of silica/kaolin clay hybrid fillers for a heavy-duty truck tire tread formulation based on NR [29] revealed that the best balance of 
heat build-up and abrasion resistance was observed at the ratio of silica/clay at $60 / 20$. The use of silica/ MMT with TESPT in SSBR/BR tread compounds improved tensile strength and traction properties at low TESPT content while enhanced modulus, hardness, wear resistance and rolling resistance at high TESPT content [31]. Substitution of 5-10 phr of silica with the sodium salt of rubber seed oil modified kaolin in NR/BR blends [32] resulted in lower Mooney viscosity, higher cure rate, increased chemical crosslink density index and bound rubber content, indicating a higher extent of rubber-rubber and filler-rubber interactions. Moreover, the mechanical properties such as abrasion resistance, compression set, tensile- and tear strength of the blend vulcanizates were enhanced, as well as the dynamic properties that are beneficial for tire tread applications. A comparison between the use of silica $60 \mathrm{phr}$ and silica/OC nanocomposite with a replacement of silica by 7 phr of OC in SBR showed that the silica/OC system gave better skid and rolling resistance with higher 100 and 300\% moduli [33]. The reduction of filler networking in silicabased elastomeric nanocomposites with exfoliated OC resulted in improved mechanical reinforcement and reduced energy dissipation [34]. Our own recent work on a hybrid filler system of silica/ OC-filled NR at 45/10 phr [11] revealed several positive effects when compared to reference pure silica-NR compounds, as the hybrid filler gave lower Payne effect (i.e. lower silica networking), higher cure rate index (i.e. better productivity in terms of reduced product cycle time), higher $\tan \delta$ at $-20^{\circ} \mathrm{C}$ (i.e. better ice traction), and lower $\tan \delta$ at $60^{\circ} \mathrm{C}$ (i.e. reduced rolling resistance).

The OC contains an organic modifying agent or cationic surfactant that is used to increase the $d$-spacing between clay layers and to change the clay surface characteristic to be more hydrophobic. The most important end groups of cationic surfactants are primary-, secondary- and tertiary-amino groups, and quaternary ammonium groups. The presence of this active surfactant in the rubber compounds also plays a role on the properties. The loading of a diamine salt of fatty acid, called a multifunctional additive, on a silica-filled NR compound [35] improved mechanical properties due to better silica dispersion and crosslink density. Modification of silica by cyclohexylamine [36] resulted in improvement of filler dispersion and mechanical properties, lower $\tan \delta$ value at $60^{\circ} \mathrm{C}$, and higher crosslink density of silica-filled
NR. The use of alkanolamide at the optimum loading (5.0 phr) for silica-reinforced NR [37] resulted in faster vulcanization and better cure torque differences, tensile strength, 100 and $300 \%$ moduli, hardness and crosslink density. An application of a multifunctional additive, $N$-phenyl- $N$ '-(gamma-triethoxysilane)-propyl thiourea (STU), in NR-silica composites resulted in a fine-dispersed structure of silica in the rubber matrix and enhanced tensile properties [38]. Based on the modification of MMT with different concentrations of octadecylamine (OCT) as organic modifying agent [39], an optimum OCT content was observed at 1.5 times the cation-exchange capacity of MMT as determined by a larger $d$-spacing of the clay and a higher degree of OC dispersion in the NR matrix that led to improved mechanical properties of the NR/OC nanocomposites. By varying the loadings of $N, N$-dimethyl- dodecylamine for MMT modification [40] for SBR-OC nanocomposites prepared by the latex mixing method that was later used to mix with silica to obtain hybrid filler compounds of silica/OC at $20 / 5 \mathrm{phr}$, with increasing the modifier content in SBR the scorch time and cure time decreased while the cure torque differences, tensile strength and wear resistance increased due to the increase of crosslink density and improved dispersion of the silicate layers in the SBR matrix.

Even though there are a large number of reports related to organoclay-rubber nanocomposites available, there is no previous work that extensively discusses the role of the nanoclay surface modifying agent on the silica-reinforced NR tire tread compounds. To fully explore and better understand the influence of the modifying agent in the $\mathrm{OC}$ that affects the rubber compound properties of a silica/OC dual system, this present work employs dimethyl dihydrogenated tallow ammonium chloride (2HT) which is a quaternary ammonium type of surfactant. The effect of modifying agent loadings on three different compound types: silica-filled NR, silica/OC-filled NR with the 2HT already included in the OC, and silica/ MMT-filled NR compounds, which contain TESPD as coupling agent, are investigated in comparison with a silica-only compound without modifying agent as reference. This is to comparatively elucidate the beneficial effect of the modifying agent when it is used for pretreated MMT (i.e. OC) or for in situ mixing of MMT in rubber, or as surface modifier for the silicarubber matrix. The mixes are subjected to characterization in terms of cure characteristics, filler-filler 
interactions, filler-rubber interactions, tensile and tear properties, DIN abrasion resistance, dynamic mechanical properties and morphology.

\section{Experimental}

\subsection{Materials}

The NR (Ribbed Smoked Sheet, RSS3) was locally produced in Thailand. Silica ULTRASIL 7005 and silane coupling agent TESPD were obtained from Evonik, Germany. Organoclay Dellite $67 \mathrm{G}$, functionalized with $47 \mathrm{wt} \%$ of $2 \mathrm{HT}, 115 \mathrm{meq} / 100 \mathrm{~g}$ of cation- exchange capacity and interlayer distance of $34.3 \AA$ A was provided by Laviosa Chimica Mineraria S.p.A, Livorno LI, Italy. Montmorillonite clay was provided by Thai Nippon Chemical Industry, Thailand. 2HT was purchased from Sigma Aldrich. The other ingredients: treated distillate aromatic extract oil (TDAE oil), diphenylguanidine (DPG), $N$-cyclohexyl-2-benzothiazyl sulfenamide (CBS), 2,2,4trimethyl-1,2-dihydroquinoline (TMQ), zinc oxide $(\mathrm{ZnO})$, stearic acid and sulfur were of commercial grade quality for the rubber industry.

\subsection{Compound preparation}

The NR based truck tire tread compounds were prepared using the formulations as shown in Tables 1-3. The amounts of TESPD and DPG were adjusted according to the silica content (Equations (1) and (2) $[41])$ :

TESPD $[\mathrm{phr}]=0.00053 \cdot Q \cdot A$

$\mathrm{DPG}[\mathrm{phr}]=0.00012 \cdot Q \cdot A$

Table 1. Formulations of silica-filled NR compounds with varying amount of modifying agent.

\begin{tabular}{|c|c|c|c|c|c|c|c|}
\hline \multirow{2}{*}{ Ingredients $^{1}$} & \multicolumn{7}{|c|}{$\begin{array}{c}\text { Amount } \\
\text { [phr] }\end{array}$} \\
\hline & Reference & 1 & 2 & 3 & 4 & 5 & 6 \\
\hline ULTRASIL 7005 & 55.0 & 55.0 & 55.0 & 55.0 & 55.0 & 55.0 & 55.0 \\
\hline $2 \mathrm{HT}$ & - & 1.2 & 2.4 & 3.5 & 4.7 & 7.1 & 9.5 \\
\hline TESPD & 5.0 & 5.0 & 5.0 & 5.0 & 5.0 & 5.0 & 5.0 \\
\hline DPG & 1.1 & 1.1 & 1.1 & 1.1 & 1.1 & 1.1 & 1.1 \\
\hline
\end{tabular}

${ }^{1}$ Remark: All formulations are with NR $100 \mathrm{phr}$, TDAE oil $8.0 \mathrm{phr}$, ZnO $3.0 \mathrm{phr}$, stearic acid $1.0 \mathrm{phr}$, TMQ $1.0 \mathrm{phr}$, CBS $1.5 \mathrm{phr}$ and sulfur $1.5 \mathrm{phr}$.

Table 2. Formulations of silica-filled NR compounds with organoclay as secondary filler.

\begin{tabular}{|c|c|c|c|c|c|c|c|}
\hline \multirow{2}{*}{ Ingredients $^{1}$} & \multicolumn{7}{|c|}{$\begin{array}{c}\text { Amount } \\
\text { [phr] }\end{array}$} \\
\hline & Reference & 1 & 2 & 3 & 4 & 5 & 6 \\
\hline ULTRASIL 7005 & 55.0 & 52.5 & 50.0 & 47.5 & 45.0 & 40.0 & 35.0 \\
\hline Dellite $67 \mathrm{G}$ & - & 2.5 & 5.0 & 7.5 & 10.0 & 15.0 & 20.0 \\
\hline TESPD & 5.0 & 4.8 & 4.5 & 4.3 & 4.1 & 3.6 & 3.2 \\
\hline DPG & 1.1 & 1.1 & 1.0 & 1.0 & 0.9 & 0.8 & 0.7 \\
\hline
\end{tabular}

${ }^{1}$ Remark: All formulations are with NR $100 \mathrm{phr}$, TDAE oil $8.0 \mathrm{phr}$, ZnO $3.0 \mathrm{phr}$, stearic acid $1.0 \mathrm{phr}$, TMQ $1.0 \mathrm{phr}$, CBS $1.5 \mathrm{phr}$ and sulfur $1.5 \mathrm{phr}$.

Table 3. Formulations of silica/MMT-filled NR compounds with varying amount of modifying agent.

\begin{tabular}{|l|c|c|c|c|c|c|c|}
\hline \multirow{2}{*}{} & \multicolumn{9}{c|}{$\begin{array}{c}\text { Amount } \\
\text { Inghr] }\end{array}$} \\
\cline { 2 - 10 } & Reference & $\mathbf{1}$ & $\mathbf{2}$ & $\mathbf{3}$ & $\mathbf{4}$ & $\mathbf{5}$ & $\mathbf{6}$ \\
\hline ULTRASIL 7005 & 55.0 & 52.5 & 50.0 & 47.5 & 45.0 & 40.0 & 35.0 \\
\hline MMT & - & 2.5 & 5.0 & 7.5 & 10.0 & 15.0 & 20.0 \\
\hline 2HT & - & 1.2 & 2.4 & 3.5 & 4.7 & 7.1 & 9.5 \\
\hline TESPD & 5.0 & 4.8 & 4.5 & 4.3 & 4.1 & 3.6 & 3.2 \\
\hline DPG & 1.1 & 1.1 & 1.0 & 1.0 & 0.9 & 0.8 & 0.7 \\
\hline
\end{tabular}

${ }^{1}$ Remark: All formulations are with NR $100 \mathrm{phr}$, TDAE oil $8.0 \mathrm{phr}$, ZnO $3.0 \mathrm{phr}$, stearic acid $1.0 \mathrm{phr}$, TMQ $1.0 \mathrm{phr}$, CBS $1.5 \mathrm{phr}$ and sulfur $1.5 \mathrm{phr}$. 
where $Q$ is the amount of silica [phr] and $A$ is the cetyl-trimethyl-ammonium-bromide (CTAB) specific surface area of the silica $\left(171 \mathrm{~m}^{2} / \mathrm{g}\right)$.

The two-step mixing procedure is displayed in Figure 1 . The first step was executed by using an internal mixer, Brabender ${ }^{\circledR}$ 50EHT, (Brabender ${ }^{\circledR} \mathrm{GmbH}$ \& Co.KG, Germany) with a mixing chamber volume of $70 \mathrm{ml}$, at a rotor speed of $60 \mathrm{rpm}$, fill factor of $70 \%$ and initial mixer temperature setting of $120^{\circ} \mathrm{C}$ in order to reach a dump temperature in the range of $135-150{ }^{\circ} \mathrm{C}$, as suggested in previous reports $[9,11]$. For silica-filled NR and silica/MMT-filled NR, all of the modifying agents were added together with the first halves of silica, TESPD and DPG. For sili$\mathrm{ca} / \mathrm{OC}$-filled NR, the OC was added with the first half of silica. The other halves of silica and TESPD were later added together with TDAE oil in the second interval of the first mixing step. The second step was for the preparation of the reactive or final compounds by mixing the obtained masterbatches with the other halves of DPG, CBS primary accelerator, and sulfur by using the same instrument operated at a rotor speed of $30 \mathrm{rpm}$, fill factor of $70 \%$, and an initial mixer temperature setting of $70^{\circ} \mathrm{C}$. The OC loadings were varied at $0-20 \mathrm{phr}$ at incremental steps, which possessed modifying agent contents from 0-9.5 phr, respectively. By taking the amounts of surface modifying agent in the $\mathrm{OC}$ as references, $2 \mathrm{HT}$

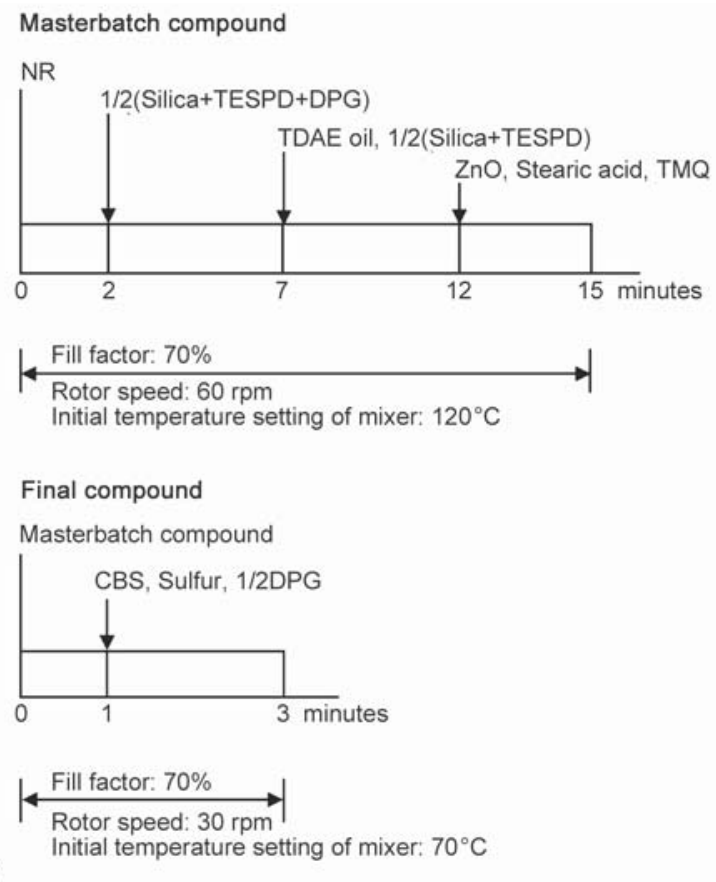

a) was added to the silica-filled NR and silica/pristine MMT-filled compounds.

\subsection{Sample characterizations \\ Characterization of filler-filler interaction: Payne effect}

The storage shear modulus $\left(G^{\prime}\right)$ of the unvulcanized rubber compounds with curatives were evaluated using a Dynamic Rubber Process Analyzer (D-RPA 3000, MonTech Rubber Testing Solutions, Germany) at a temperature of $100^{\circ} \mathrm{C}$, frequency of $0.5 \mathrm{~Hz}$ and varying strains in the range of $0.56-$ $100 \%$. The Payne effect was calculated from the difference in $G^{\prime}$ at low strain $(0.56 \%)$ and high strain $(100 \%)$.

\section{Characterization of bound rubber content (BRC)}

An amount of $0.25 \mathrm{~g}$ of uncured compound (without curatives) was put into a metal cage and immersed in $40 \mathrm{ml}$ of toluene for 7 days at room temperature, while the toluene was renewed every day. Then the sample was removed from the toluene, dried at $105^{\circ} \mathrm{C}$ in an oven for $24 \mathrm{~h}$ and weighed. The bound rubber content was calculated using Equation (3):

$B R C[\%]=\frac{m-m_{\mathrm{s}}}{m_{\mathrm{r}}} \cdot 100$
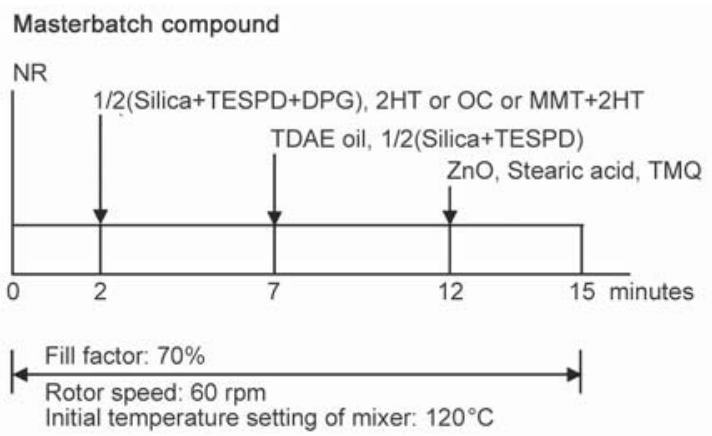

Final compound

Masterbatch compound

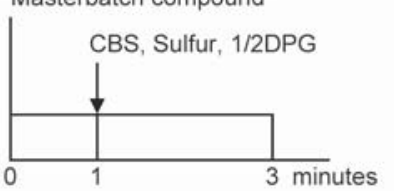

$\underset{\text { Rotor speed: } 30 \mathrm{rpm}}{\stackrel{\text { Fill factor: } 70 \%}{\longrightarrow}}$

b)

Initial temperature setting of mixer: $70^{\circ} \mathrm{C}$

Figure 1. Two-step mixing procedures for compound preparations: (a) NR/silica without clay MMT or OC, nor 2HT; (b) NR/silica $+2 \mathrm{HT}, \mathrm{NR} /$ silica $+\mathrm{OC}$ and NR/silica+MMT+2HT compounds. 
where $m$ is the weight of sample after extraction, $m_{\mathrm{s}}$ and $m_{\mathrm{r}}$ are the weights of filler and rubber in the original sample respectively.

\section{Cure characteristics.}

The compounds were measured by using the D-RPA 3000 , at a temperature of $150^{\circ} \mathrm{C}$, frequency $0.833 \mathrm{~Hz}$ and $2.79 \%$ strain for 30 minutes. The CRI was calculated to equal $\left[100 /\right.$ (optimum cure time $\left(t_{\mathrm{c} 90}\right)-$ scorch time (ts2)].

\section{Tensile and tear properties}

The compounds were vulcanized for their optimum cure times $\left(t_{\mathrm{c} 90}\right)$ by using a compression molding press (CT Compression Machine, Charoen Tut Co, Ltd, Samut Sakhon, Thailand) at $150^{\circ} \mathrm{C}$ and 100 bars into $2 \mathrm{~mm}$ thick sheets. For tensile properties, Type 2 dumb-bell test specimens were die-cut from the presscured sheets and tests were carried out with a tensile tester (Hounsfield Test Equipment Co., Ltd., Surrey, England) at a crosshead speed of $500 \mathrm{~mm} / \mathrm{min}$ according to ISO 37. For tear strength, the vulcanized rubbers were tested at room temperature using Delfttype specimens with a Zwick tensile tester Model Z1.0/TH1S (Zwick Roell Group, Ulm, Germany) and the same crosshead speed as applied for tensile tests according to ISO 34-2.

\section{Apparent crosslink density}

Vulcanizate samples with a dimension of $3 \times 5 \times 2 \mathrm{~mm}^{3}$ were immersed in toluene at room temperature for 7 days. Thereafter, the swollen samples were taken out and blotted lightly with paper to remove excess toluene from the surface. The weights of the rubbers before and after swelling were measured and the swelling ratio $(Q)$ was calculated according Equation (4):

$Q=\frac{M_{\mathrm{t}}-M_{0}}{M_{0}}$

where $M_{0}$ and $M_{\mathrm{t}}$ are the weights of the samples before and after swelling, respectively. The apparent crosslink density was calculated from the reciprocal of swelling ratio (i.e. 1/Q) [42], because the real crosslink density by for example the Flory-Rehner approach [43] is not feasible to acquire with the varying filler loadings.

\section{DIN abrasion resistance index (ARI) and its abraded surface}

The $A R I$ was tested using a DIN abrader (GOTECH Testing Machines Inc, Taichung, Taiwan) according to method A of ISO 4649. The test specimens had a diameter of $16 \pm 2 \mathrm{~mm}$ with a minimum thickness of $6 \mathrm{~mm}$. The pure silica-filled NR without 2HT was used as reference rubber. The $A R I$ was calculated according to Equation (5):

$$
A R I=\frac{\Delta m_{\mathrm{r}} \cdot d_{\mathrm{t}}}{\Delta m_{\mathrm{t}} \cdot d_{\mathrm{r}}} \cdot 100
$$

where $\Delta m_{\mathrm{r}}$ is mass loss of the reference rubber [g], $d_{\mathrm{r}}$ is density of the reference rubber $\left[\mathrm{g} / \mathrm{cm}^{3}\right], \Delta m_{\mathrm{t}}$ is mass loss of the test rubber $[\mathrm{g}]$, and $d_{\mathrm{t}}$ is density of the test rubber $\left[\mathrm{g} / \mathrm{cm}^{3}\right]$.

The DIN abraded surface was characterized by scanning electron microscopy (SEM, Quanta 400, FEI Company, the Netherlands). The surface was coated with gold prior to being analyzed.

\section{Dynamic mechanical properties}

The loss tangent or $\tan \delta$ at $60^{\circ} \mathrm{C}$ of the vulcanizates was determined using the D-RPA 3000 at strain $3.49 \%$ with varying frequencies in the range of 0.05 $33.00 \mathrm{~Hz}$. The samples were cured in the RPA chamber at $150^{\circ} \mathrm{C}$ to reach their optimum cure times before being tested. In addition, dynamic mechanical properties of silica-filled NR vulcanizates under a temperature sweep from -80 to $80^{\circ} \mathrm{C}$ were characterized by using a Metravib Viscoanalyzer VA 2000. The samples of a dimension of $6 \times 4 \times 2 \mathrm{~mm}^{3}$ were tested in tension mode at a frequency of $10 \mathrm{~Hz}$ and $0.1 \%$ strain. Tan $\delta$ values at $-20,0{ }^{\circ} \mathrm{C}$ are used as indicative for ice traction and wet grip respectively, and $\tan \delta$ at $60^{\circ} \mathrm{C}$ is to indicate rolling resistance of a tire tread.

\section{Results and discussion}

\subsection{Filler-filler and filler-rubber interaction}

The difference between the values of the storage modulus at low strain $(0.56 \%)$ and high strain $(100 \%)$ indicates the Payne effect that reflects the level of fillerfiller interaction [44] as shown in Figure 2a. The increase of the modifying agents greatly reduces the Payne effect of all types of compounds to similar levels indicating a further reduction of filler networking 

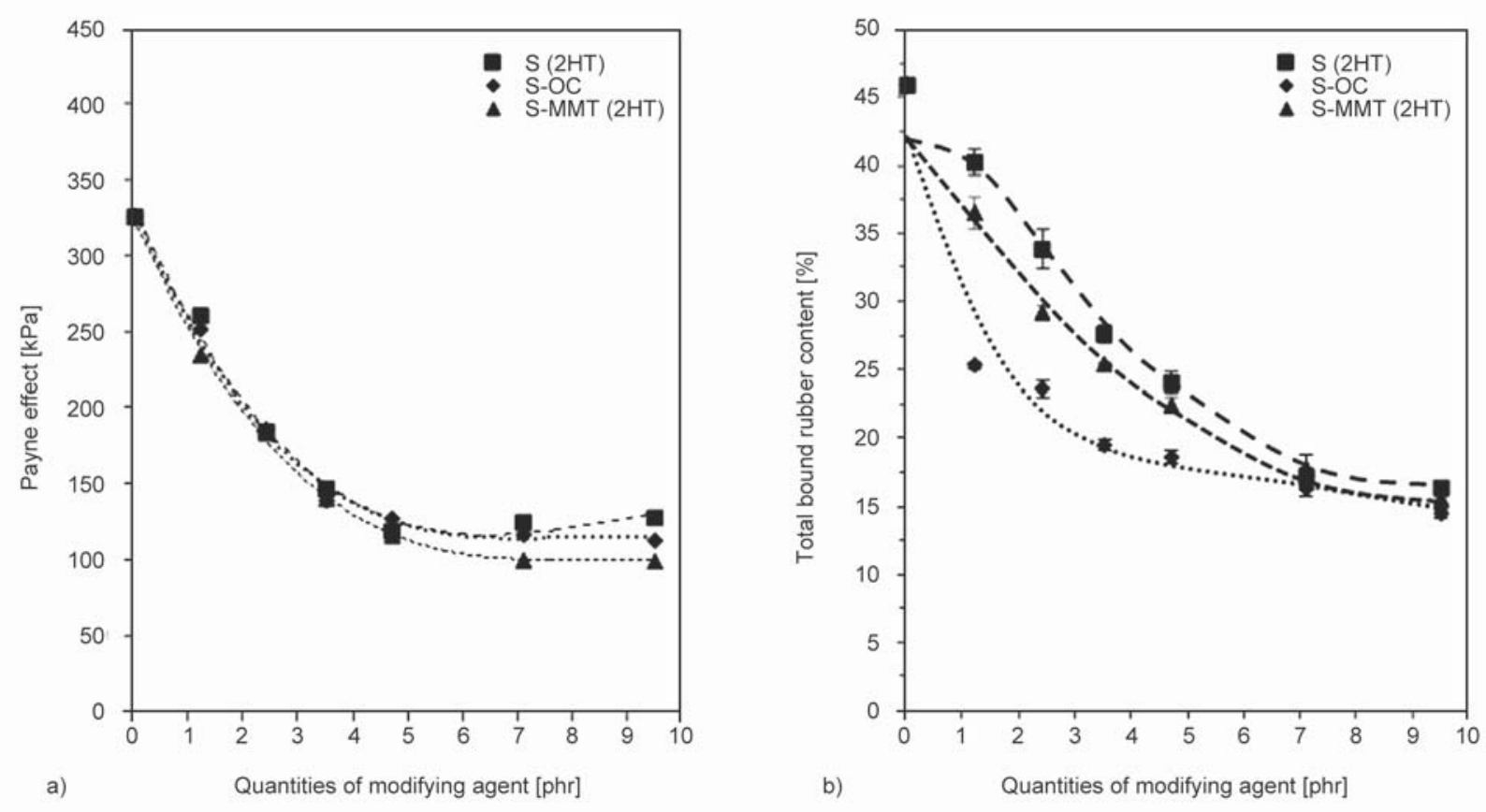

Figure 2. Payne effect (a) and bound rubber content (b) of silica-filled NR, silica/OC-filled NR and silica/MMT-filled NR compounds with varying loadings of modifying agent $2 \mathrm{HT}$.

by the presence of $2 \mathrm{HT}$, in addition to the effect of the silanization reaction between the alkoxy groups of TESPD and the silanol groups of the silica. As only a portion of the silanol groups could react with the silane due to the limited accessibility after the first silane molecules are grafted on to the silica surface, it has been reported that the availability of alcohols or amines to shield and increase the hydrophobization of the silica surface is helpful $[45,46]$. By the incorporation of $2 \mathrm{HT}$ into the compounds, better hydrophobization and filler dispersion in the rubber matrix is obtained. Moreover, this $2 \mathrm{HT}$ may also enhance the silanization because of its basicity. The Payne effect of all the compounds decreases sharply with increasing modifying agent loadings up to $4.7 \mathrm{phr}$ and thereafter tends to level off. This reduction in filler networking by the modifying agent is in accordance with work reported by Galimberti and co-workers for silica-based nanocomposites [34]. The presence of the quaternary ammonium salt also plasticizes the system and results in the reduction of the modulus of the filled-rubber, as observed in the range of high strain after the breakdown of the filler network.

The decrease of filler-rubber interaction is also reflected in the reduction of bound rubber content [47] as shown in Figure 2b. The sharp drop in bound rubber content with increasing modifying agent is in accordance with the fall in Payne effect in Figure 2a.
These results together indicate that the incorporation of $2 \mathrm{HT}$ as surface modifying agent contributes to physical interactions rather than chemical interactions. When comparing the bound rubber contents of the three systems, the silica-filled NR shows a higher bound rubber content than silica/MMT and silica/ OC-filled NR. This indicates that the silica-filled NR with silane coupling agent has a higher filler-rubber interaction than the mixes with dual fillers of sili$\mathrm{ca} / \mathrm{MMT}$ or OC. The reduction of bound rubber content was also observed in a carbon black/OC system due to the influence of the clay surface modifying agent [48].

\subsection{Cure properties}

Based on the cure characteristics shown in Figure 3 for all compound types, the incorporation of modifying agent clearly suppresses filler flocculation before the onset of vulcanization when compared to the pure silica without $2 \mathrm{HT}$ in which the flocculation is noticeably observed despite the use of TESPD in combination with silica. This filler flocculation manifests itself by the initial hub in the curing curve, before real vulcanization takes over. The addition of modifying agent has a strong influence on both cure torques and times. The minimum cure torque $\left(M_{\mathrm{L}}\right)$ indicates compound viscosity which is generally related to molecular chain entanglements of the polymer and filler-related parameters like type, amount, 
filler-rubber interaction and filler-filler interaction or the filler network. When the filler content is increased and the formation of the filler network is enhanced, the $M_{\mathrm{L}}$ increases [49]. With increasing the modifying agent content in the silica-filled compounds, the $M_{\mathrm{L}}$ gradually reduces. As seen in Figure 2a, the Payne effect is greatly reduced by the addition of $2 \mathrm{HT}$, so the filler-filer interaction is disrupted. In addition, the bound rubber content is also decreased with increasing the 2HT content. So, there is less obstruction to flow. Moreover, the modifying agent has a long tail structure of dihydrogenated tallow that can plasticize the system, causing increasing free volume between the high molecular weight elastomer chains to facilitate flow. Meanwhile, the polar functional groups
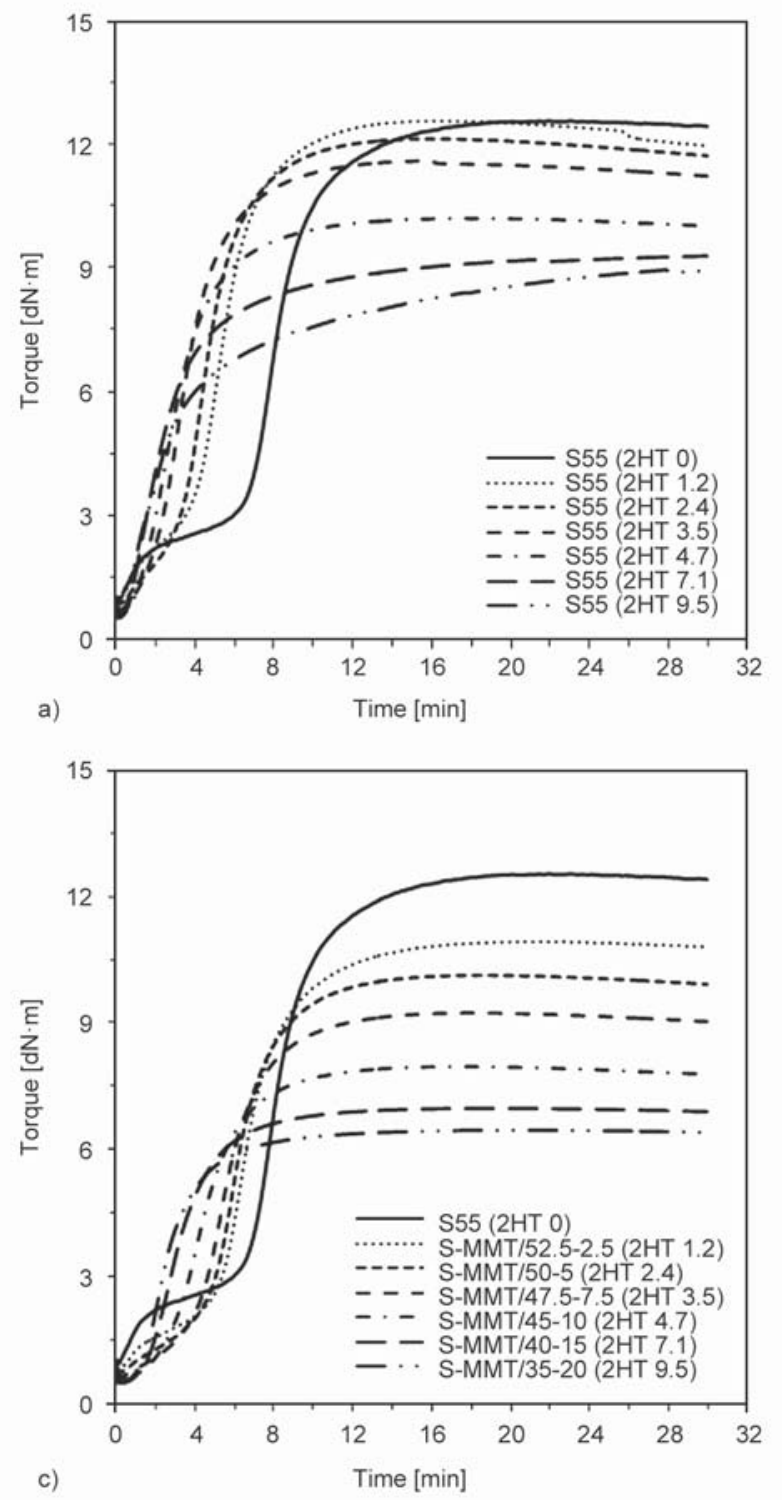

that are present in the modifying agent $(\mathrm{C}=\mathrm{O}, \mathrm{C}-\mathrm{O}$ and $-\mathrm{N}=$ ) can interact with the left-over free silanol groups on the silica surface after the silanization reaction, providing a shielding effect that promotes hydrophobicity and interfacial compatibility between rubber and filler. For these various reasons, the rubber compound viscosities of every filler system: i.e. silica, silica/OC and silica/MMT, are remarkably decreased with increasing the modifying agent loading causing improved processability. It has been reported before that by substituting silica with OC, the compound viscosity was similarly affected $[34,50]$. After vulcanization, the cure torque differences $\left(M_{\mathrm{H}}-M_{\mathrm{L}}\right)$ of the silica-, silica/OC- and silica/MMTfilled NR compounds with different modifying agent
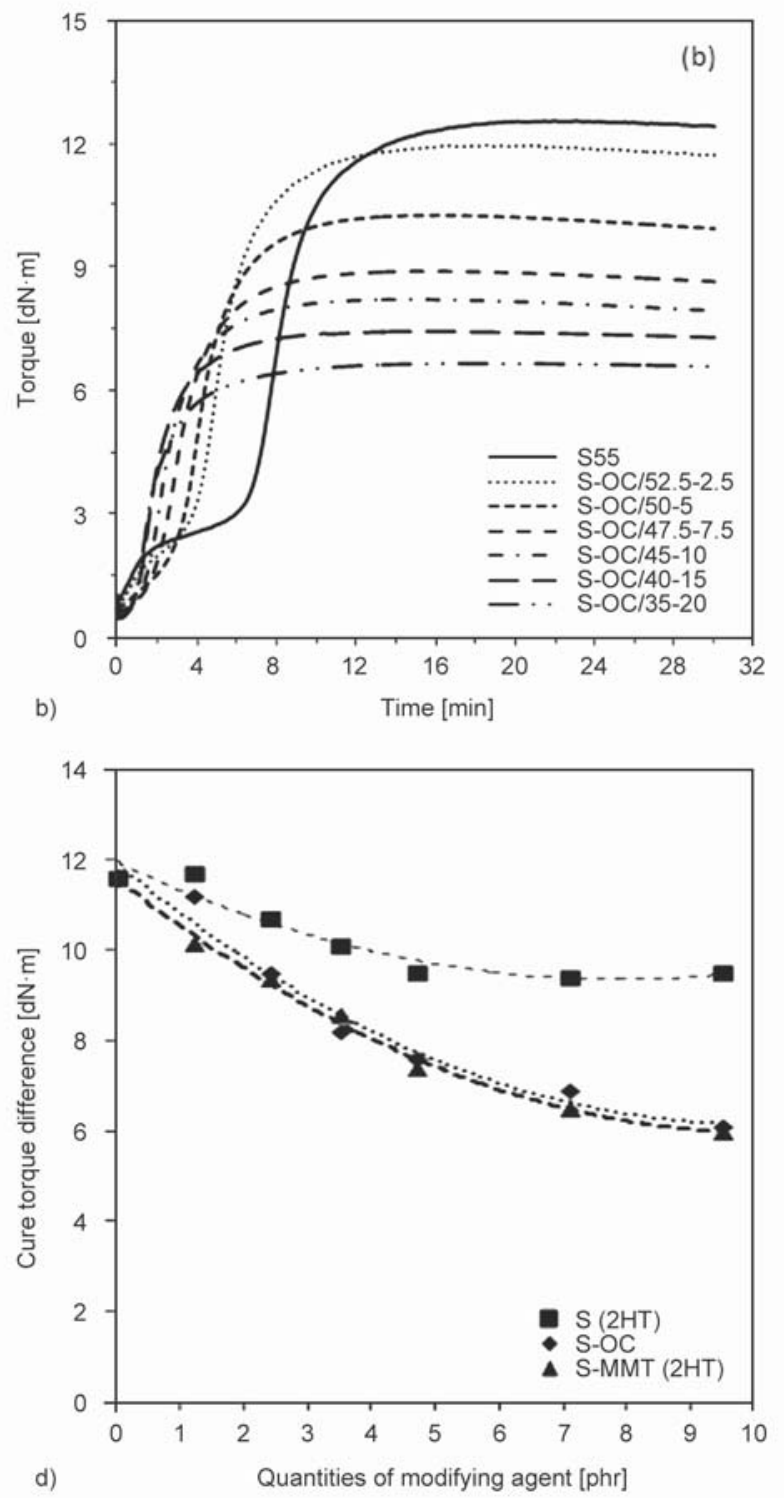

Figure 3. The effect of loadings of modifying agent (2HT) on the cure profiles of silica-filled NR (a), silica/OC-filled NR (b), and silica/MMT-filled NR (c) compounds, with varying loadings of modifying agent 2HT; and their cure torque differences (d). 
loadings are shown in Figure 3d. Since the rheometer torque increases by formation of crosslinks, the cure torque difference or delta torque is related to the crosslink density. However, the levels of $M_{\mathrm{H}}-M_{\mathrm{L}}$ which indicate the vulcanizate stiffness are also influenced by several additional factors, combining contributions from chemical crosslinks by the vulcanization reaction, filler-rubber interactions and filler-filler interactions. As displayed in Figure 3d, the $M_{\mathrm{H}}-M_{\mathrm{L}}$ of all the compound types decrease when the modifying agent content is increased, but to different levels. The silica/OC-filled and silica/ MMT-filled NR compounds show similar behaviors and the reduction in $M_{\mathrm{H}}-M_{\mathrm{L}}$ is much larger compared with the pure silica-filled NR. As the fillerfiller interactions or Payne effect (Figure 2a) and filler-rubber interactions as indicated by bound rubber contents (Figure $2 \mathrm{~b}$ ) are not much different, the clear difference in $M_{\mathrm{H}}-M_{\mathrm{L}}$ of silica only-filled NR when compared to the mixes with OC and MMT is most likely derived from the filler network reformed due to flocculation, as distinctively displayed on the cure curves (Figure 3 ). The reduction of the cure torque difference when the modifying agent loading is raised, in addition to the reduced filler-filler and filler-rubber interaction with excess amount of the modifying agent, means that the crosslink density may be reduced as a result of diluting effects and interference with the polar curatives.

As the modifying agent is an amino-based compound composed of an ammonium salt, it has an accelerating effect on the vulcanization reaction, that can be beneficial by reducing the required processing cycle time. The increasing loadings of modifying agent progressively shorten scorch time of all the compound types studied, but a different behavior is observed for the cure time. For the silica/OC- and silica/MMT-filled NR compounds, the cure times are gradually reduced with increasing the modifying agent content, but for silica-filled NR the cure time decreases to reach a minimum at the $2 \mathrm{HT}$ content of $3.5 \mathrm{phr}$ and thereafter increases again. As observed in Figure 3, the cure curves of silica-filled NR with the addition of 2HT start to show marching modulus torques when the modifying agent loading reaches $4.7 \mathrm{phr}$ and marching is more pronounced at 7.1 and $9.5 \mathrm{phr}$ of $2 \mathrm{HT}$. In this pure silica system wherein the optimum content of silane coupling agent is used, the addition of the polar compound like the modifying agent in excess amounts may cause interference with the vulcanization reaction, possibly due to interactions between the modifying agents and accelerators. For the compounds containing silica and OC or MMT, the delaminated clay introduces more polar functional groups on the edges that the modifying agent needs to shield. So, in these systems, there will be less free modifying agent to interrupt the vulcanization reaction. Comparing among the three systems, the use of silica/OC results in the shortest scorch time and cure time as the surface of pretreated OC should be most efficiently protected by the modifying agent. The effect of modifying agent in OC on accelerating the curing reactions has been previously documented by various authors [40, 51-58]. Overall, the benefit of adding $2 \mathrm{HT}$ in either form is that it substantially reduces the scorch time and optimum cure time, which otherwise are comparatively long in comparison with silica reinforced compounds. This greatly improves the vulcanization processability of pure silica reinforced compounds [59].

\subsection{Mechanical properties and apparent crosslink density}

The effect of modifying agent loadings on tensile and tear properties of silica-filled NR, silica/OCfilled NR and silica/MMT-filled NR compounds are shown in Figure 4. The $100 \%$ moduli of all the compound types are quite similar with a tendency to reduce slightly with increasing modifying agent content. However, the modulus values at $300 \%$ elongation are different (Figure 4a). The silica/MMT-filled NR shows the lowest $300 \%$ modulus which decreases with increase of the modifying agent loading. While the $300 \%$ modulus of silica-filled NR and silica/OC-filled NR compounds show optimum values. The addition of small amounts of modifying agent increases the $300 \%$ modulus first but soon reaches a maximum and thereafter reduces. Optimum values are observed for 3.5 and $2.4 \mathrm{phr}$ of $2 \mathrm{HT}$ for silicafilled- and silica/OC-filled NR compounds, respectively. For the silica/OC system, the optimum of $300 \%$ modulus is observed at a loading of OC of $5 \mathrm{phr}$ which corresponds to $2.4 \mathrm{phr}$ of modifying agent. The lowest modulus overall of the silica/MMT-filled system indicates poorest compatibility with the rubber matrix. The lower reinforcement effect of silica/MMT hybrid filler in rubber compounds compared to conventional silica was previously observed $[30,31]$ and interpreted as a result of hydrogen bonding between the silica and the polar surface of MMT 
that lowers the compatibility between MMT and the non-polar rubber [20]. At higher content of modifying agent, a plasticizing effect becomes dominant and so the rubber vulcanizates show less resistance to deformation at moderate $300 \%$ elongation. It should be noted that for the filled systems, in addition to crosslink density, more complications arise from filler-rubber interactions, filler networking and interfacial adhesion between filler and the rubber phase. The properties therefore can vary depending on the dominant factor in that compound.

Tensile strength of silica-filled NR, silica/OC-filled NR and silica/MMT-filled NR compounds increases slightly or remains at a similar level when the amount of modifying agent added is low as shown in Figure $4 \mathrm{~b}$. But this property starts to drop clearly after the modifying agent loading exceeds $4.7 \mathrm{phr}$ as a result of a plasticizing effect and lower bound rubber
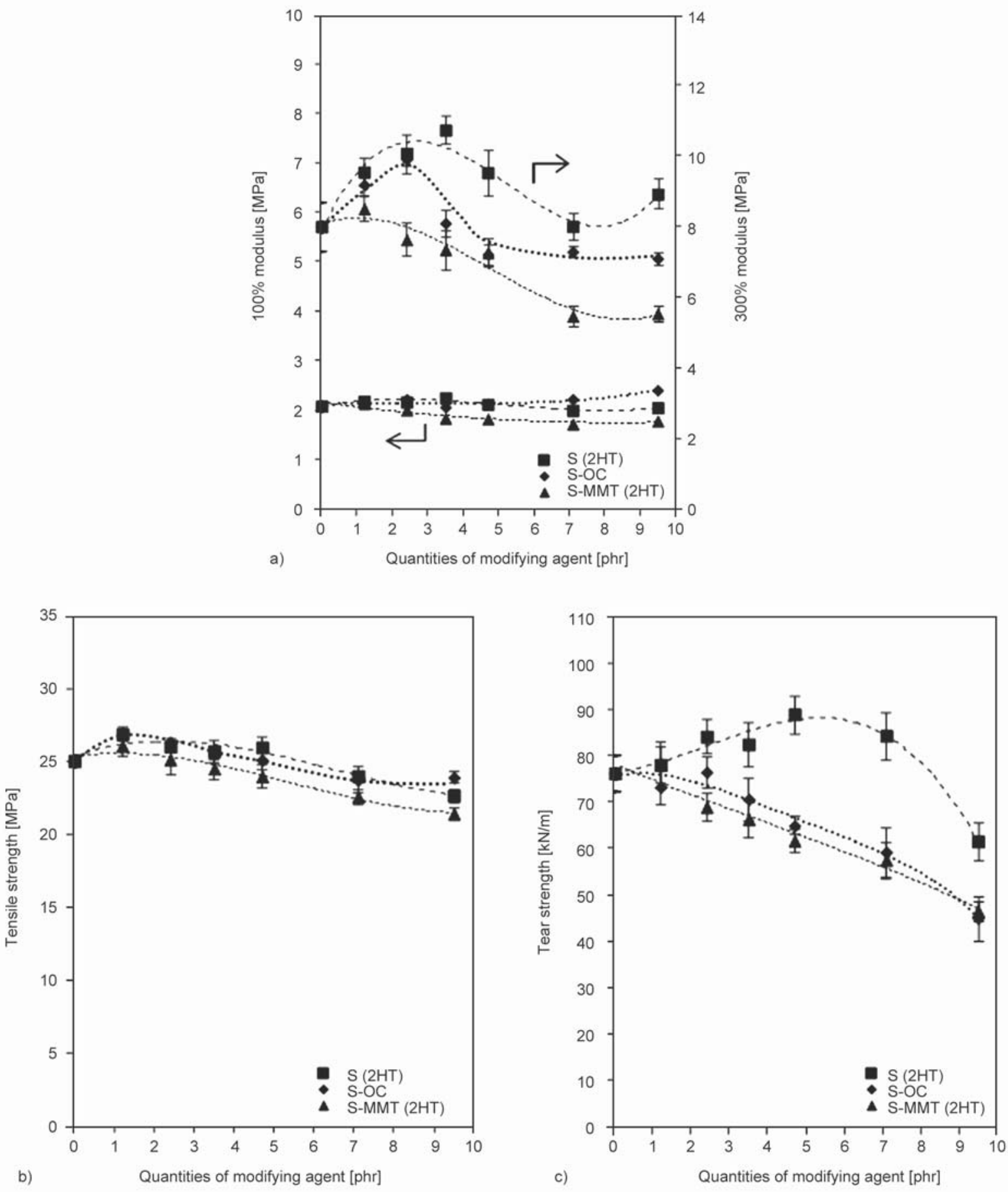

Figure 4. Modulus at 100 and 300\% strains (a), tensile strength (b) and tear strength (c) of silica-filled NR, silica/OC-filled NR and silica/MMT-filled NR compounds with varying loadings of modifying agent $2 \mathrm{HT}$. 

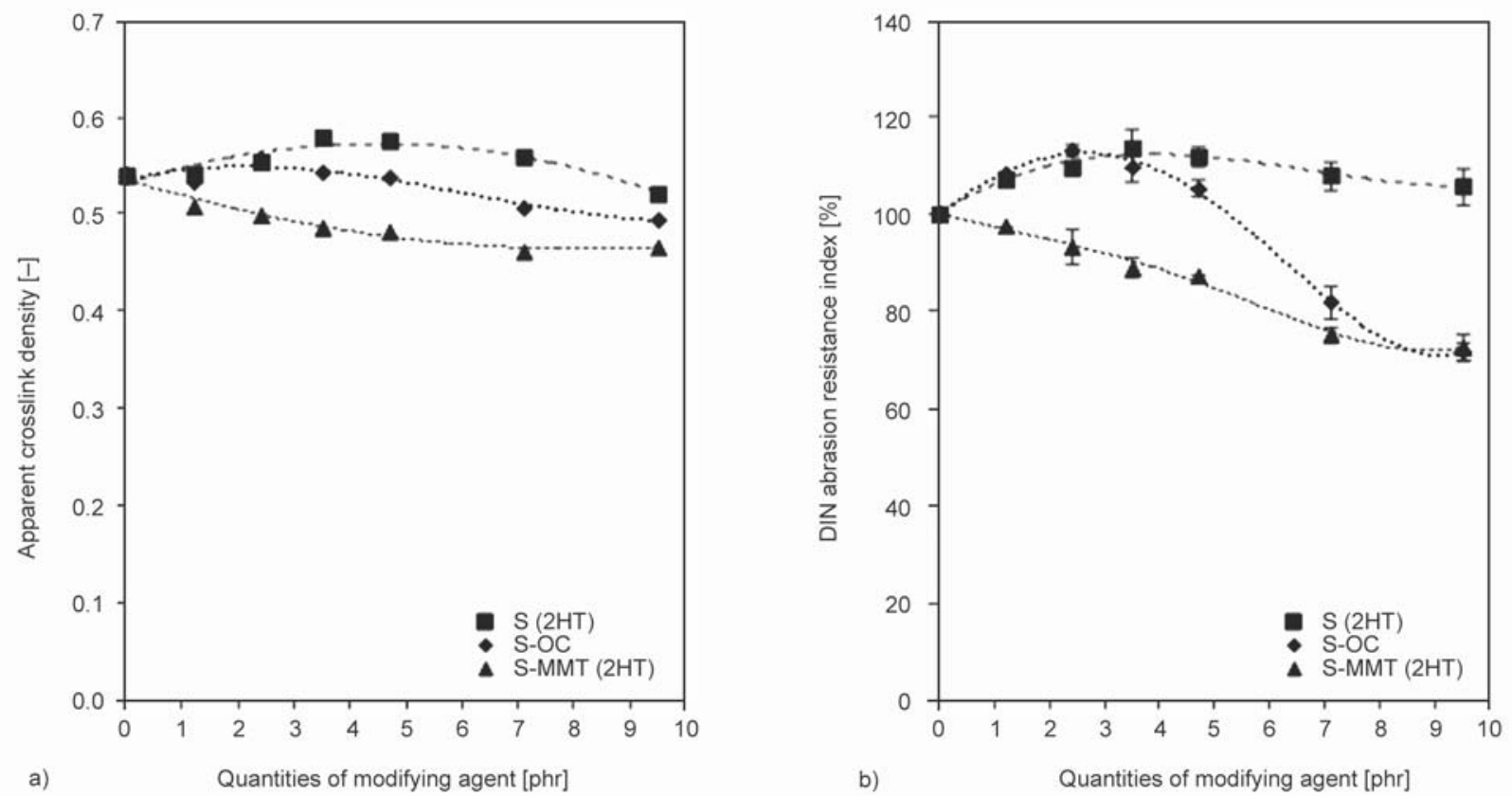

Figure 5. Apparent crosslink density (a) and DIN abrasion resistance index (b) of silica-filled NR, silica/OC-filled NR and silica/MMT-filled NR compounds with varying loadings of modifying agent $2 \mathrm{HT}$.

content, in correspondence with a reduction of the apparent crosslink density as shown in Figure 5a. Tear strength (Figure 4c) shows a different response, to increase with the modifying agent loading in the compounds of silica-filled NR. It shows enhanced tear strength with increasing modifying agent loading up to $4.7 \mathrm{phr}$ and thereafter decreases, whilst the silica/OC- and silica/MMT-filled vulcanizates show a continuous drop in tear strength. The loadings of modifying agent also have an influence on DIN abrasion resistance index as shown in Figure 5b. Silicafilled NR has the highest abrasion resistance and the incorporation of $2 \mathrm{HT}$ improves this property when compared with the one without. The silica/OC-filled NR shows an optimal DIN abrasion resistance index at $2.4 \mathrm{phr}$ of modifying agent or at $5 \mathrm{phr}$ for OC. But for silica/MMT-filled compounds, the DIN abrasion resistance index drops gradually with increasing amount of modifying agent.

\subsection{SEM images of DIN abraded surfaces}

The SEM images of the DIN abraded samples of silica-filled NR, silica/OC-filled NR and silica/MMTfilled NR compounds containing different loadings of modifying agent are analyzed in comparison with that of pure silica-filled NR without modifying agent, as shown in Figure 6. The abrasion patterns of the DIN abraded surfaces agree well with the DIN abrasion resistance indices. The silica-filled compounds that have a higher DIN abrasion resistance index show smoother abraded surfaces when compared to the silica/OC- and silica/MMT-filled compounds. The silica-filled NR with $9.5 \mathrm{phr}$ of modifying agent in which the abrasion resistance starts to decrease shows more tear lines and larger asperities. For the silica/OCfilled NR compound that shows optimum abrasion resistance at the modifying agent of $2.4 \mathrm{phr}$, the abraded surface is clearly smoother than those with 4.7 and $9.5 \mathrm{phr}$ of modifying agent. The lowest abrasion resistance of silica/MMT-filled NR compounds results in abraded surfaces with larger asperities and rougher surfaces. The asperities of the weaker material with higher loading of modifying agent can be torn off easier and become more visible on the abrasion patterns. The results are corresponding with their mechanical properties as tensile strength, $300 \%$ modulus, tear strength and apparent crosslink density.

Overall, the silica only-filled NR compound shows better mechanical properties than the silica/clay dual filler systems. The use of silica/TESPD as silane coupling agent with a small amount (2.4-4.7 phr) of $2 \mathrm{HT}$ further improves the mechanical properties, i.e. $300 \%$ modulus, tear strength and abrasion resistance, as this modifying agent could provide an additional shielding effect on the silica surface. For silica/clayfilled compounds, the silica/OC gives better mechanical properties than the silica/MMT. The pre-modified OC gives a higher apparent crosslink density that is derived from better filler-rubber interaction compared to the use of pristine MMT with modifying 

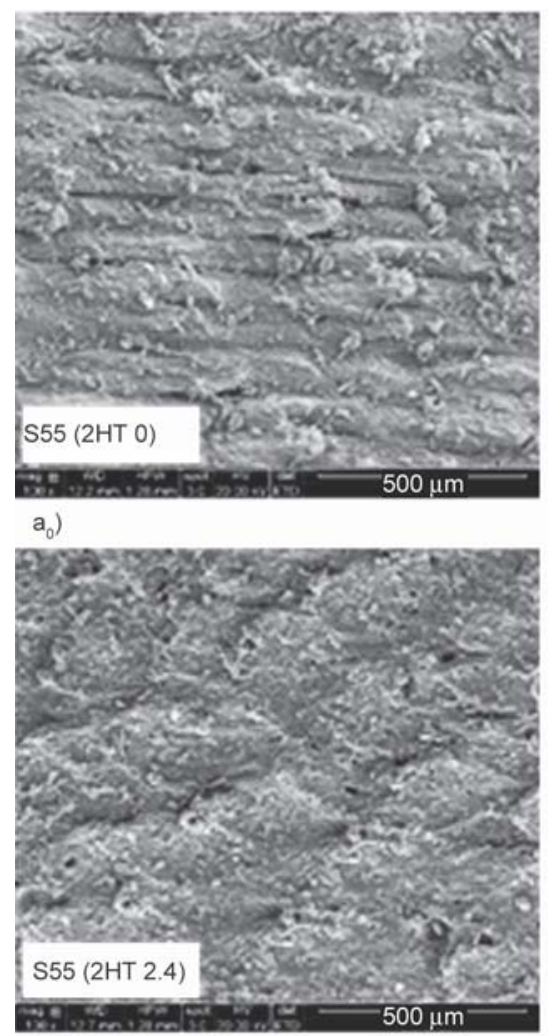

$\left.a_{1}\right)$
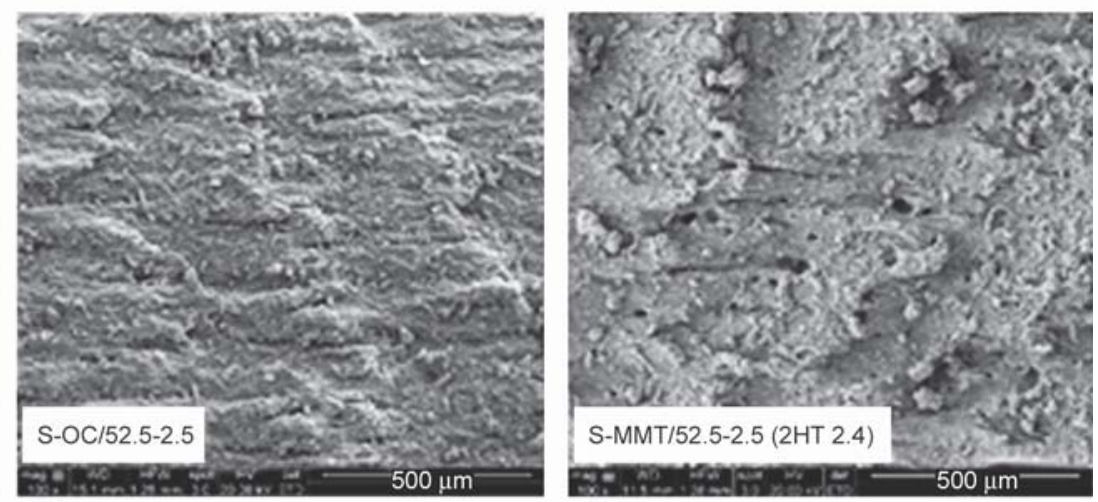

$\left.b_{1}\right)$

$\left.c_{1}\right)$
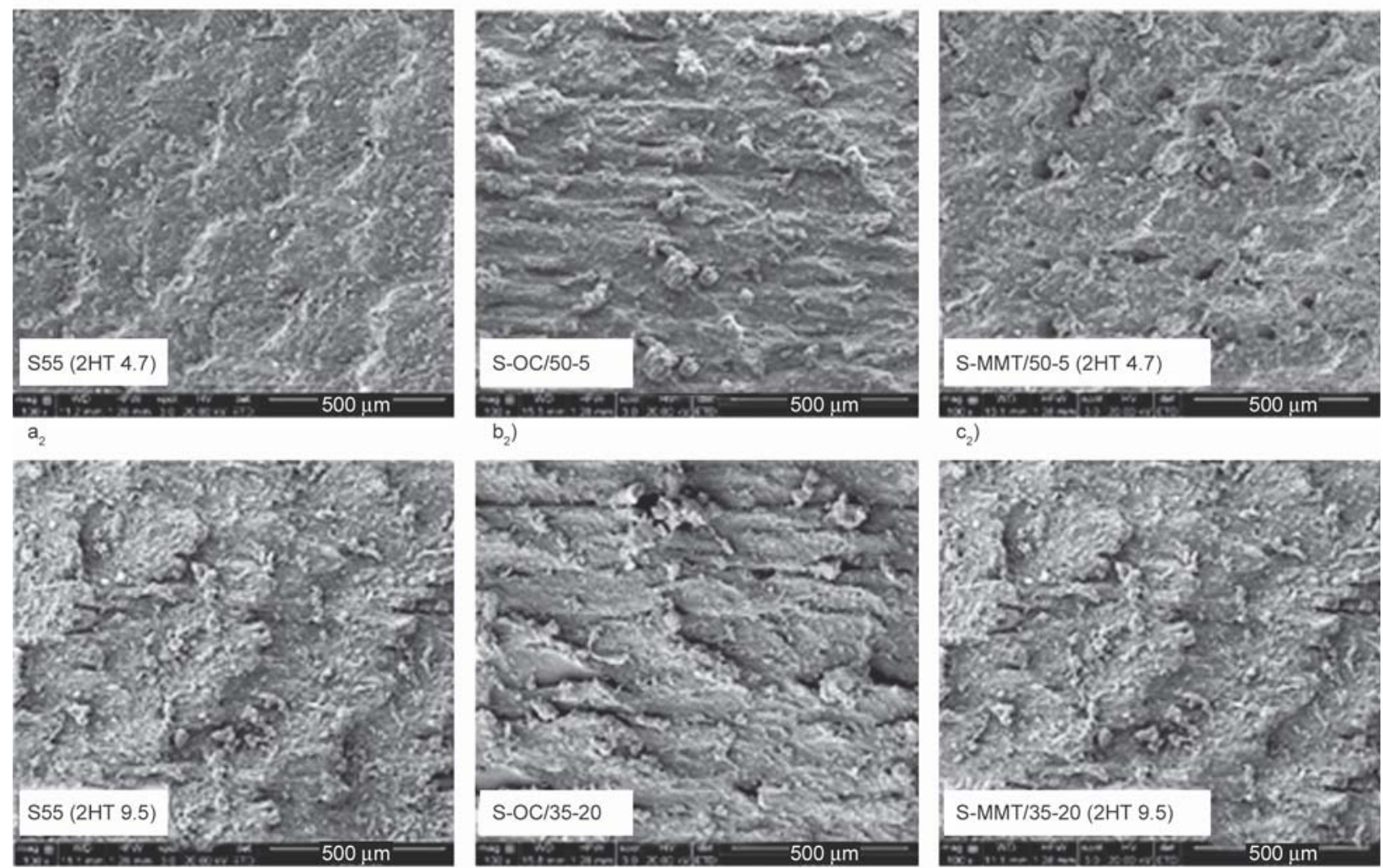

$\left.a_{3}\right)$

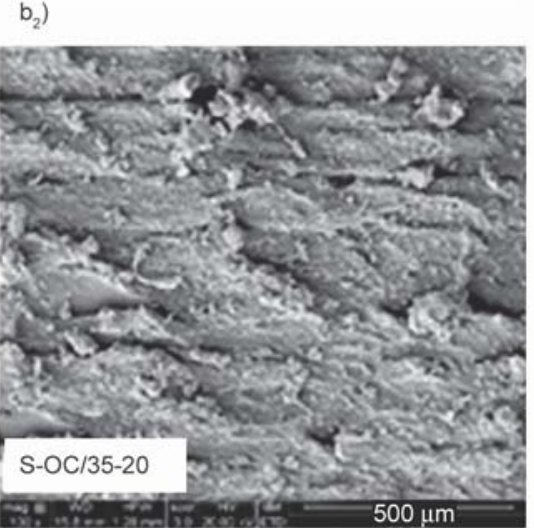

$\left.b_{3}\right)$

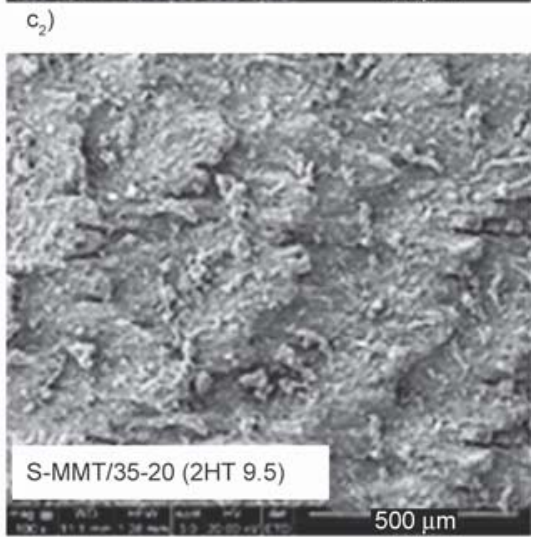

$\left.\mathrm{C}_{3}\right)$

Figure 6. SEM photographs of DIN abraded surfaces of silica-filled NR (a), silica/OC-filled NR (b) and silica/MMT-filled NR (c) compounds with varying loadings of modifying agent $2 \mathrm{HT}(0-3)$.

agent added in situ during mixing. The optimum properties of silica/OC-filled NR are observed at $5 \mathrm{phr}$ of OC that contains 2.4 of modifying agent.

\subsection{X-ray diffraction (XRD)}

Figure 7a shows the X-ray diffraction (XRD) patterns of Na-MMT and 2HT-modified Na-MMT 

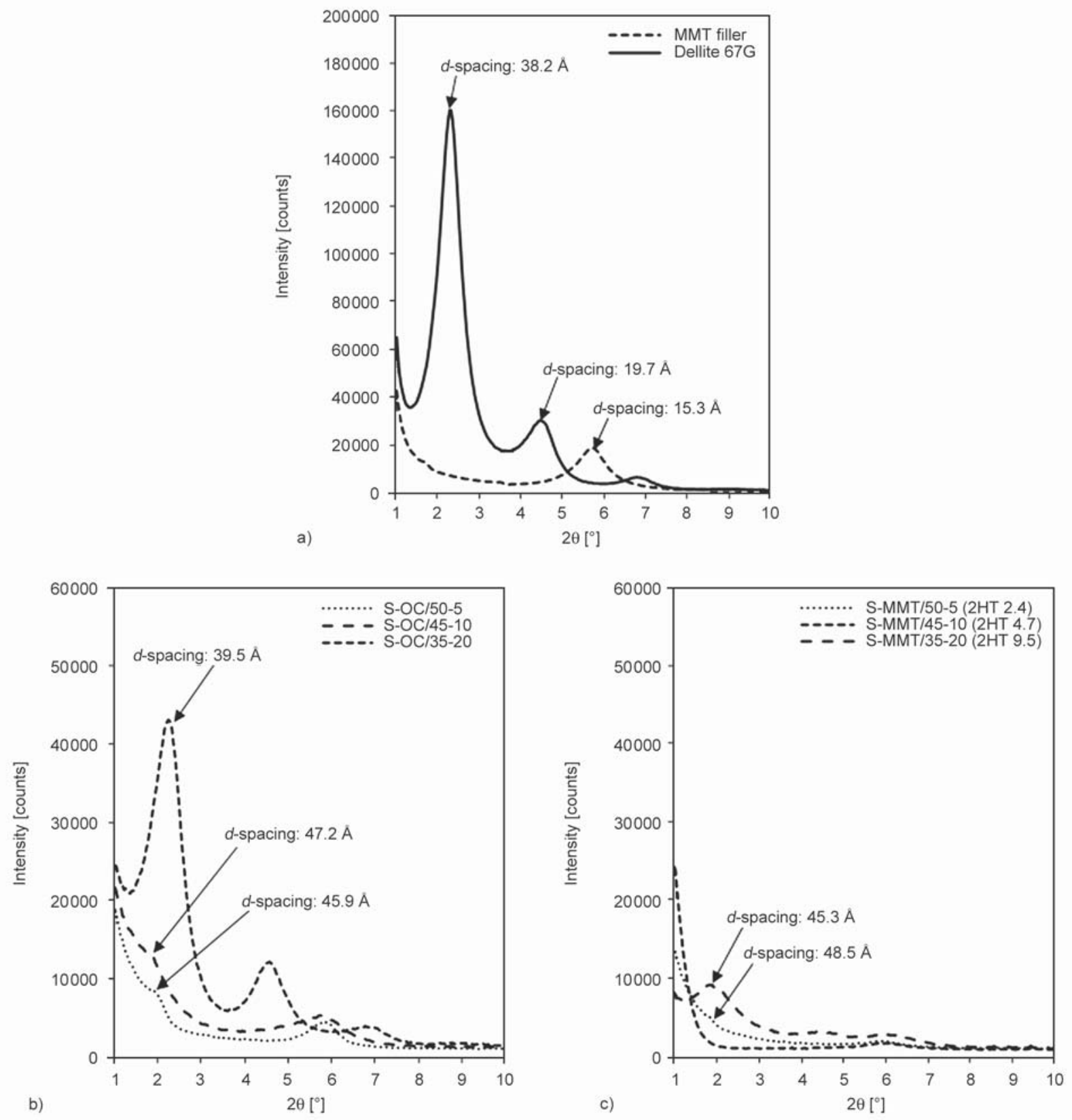

Figure 7. X-ray diffraction patterns and interlayer spacing of unmodified MMT and organically modified clay (a), silica/OCfilled NR (b), and silica/MMT-filled NR (c) compounds with varying loadings of modifying agent 2HT.

(OC). By applying Bragg's law, the interlayer spacing, called $d$-spacing, of the clay platelets can be determined. The maximum peaks of $\mathrm{OC}$ are shifted towards smaller $2 \theta$ angles than for the unmodified Na-MMT, indicating a larger $d$-spacing. The XRD pattern of Na-MMT shows a single peak of $2 \theta$ at $5.7^{\circ}$ which corresponds to a $d$-spacing of $15.4 \AA$. The OC shows three peaks of $2 \theta$, of which the two larger ones are at 2.3 and $4.5^{\circ}$ that correspond to $d$-spacings at 38.2 and $19.7 \AA$, respectively. The larger $d$-spacing corresponding to the highest peak for $\mathrm{OC}$ is caused by the insertion of modifying agent molecules into the galleries of the pristine clay platelets. It was shown previously that the $\mathrm{OC}$ with intercalated organic layers was due only to low molecular mass substances, essentially the ammonium cation, and no evidences for intercalation of polymer chains between two consecutive layers were observed $[60,61]$.

The XRD patterns of silica/OC-filled NR and silica/ MMT-filled NR compounds with different amounts of modifying agent are shown in Figures 7b, 7c. Figure $7 \mathrm{~b}$ shows the rubber specimens that contain modifying agent at 2.4, 4.7 and $9.5 \mathrm{phr}$ or 5, 10 and $20 \mathrm{phr}$ of the OC. An increased $d$-spacing is observed for 2.4 and $4.7 \mathrm{phr}$ of modifying agent in the $\mathrm{OC}$ and the $\mathrm{XRD}$ patterns indicate that the $\mathrm{OC}$ is well intercalated 
in the NR matrix because the peak at $2 \theta$ around $2^{\circ}$ is only vaguely visible. However, at $9.5 \mathrm{phr}$ of modifying agent or $20 \mathrm{phr}$ of $\mathrm{OC}$, the characteristic peaks of OC are clearly visible again with a $d$-spacing of $39.5 \AA$ which is almost the same value as that of the pure OC (Figure 7a), indicating improper dispersion of the $\mathrm{OC}$ at such high concentration. It has been reported previously for organomodified clay (Cloisite 20A)-filled NR that an exfoliated structure was obtained at an OC concentration of 5 phr [57]. It remains a point of discussion whether the vague visibility of the OC-peaks at low loadings is a sign of exfoliation, or just a too low concentration to be able to be properly visible. The silica/MMT-filled NR compounds with varied loadings of modifying agent show different XRD patterns compared to that of silica/OC. The results in Figure 7c show that the materials having MMT of 5 and $10 \mathrm{phr}$, or with 2.4 and $4.7 \mathrm{phr}$ of modifying agent, respectively, show no clear characteristic peaks of clay, which is often claimed to be an indication of exfoliation, but in the present case must be due to a too low concentration of the clay to be clearly visible [34]. However, at higher loading of MMT and modifying agent, i.e. at $20 \mathrm{phr}$ of MMT and $9.5 \mathrm{phr}$ of modifying agent, the silica/MMT-filled NR displays a clear peak again at the interlayer distance at $45.3 \AA$, indicating improper dispersion again of MMT in the NR matrix at high concentration as observed also in the case of silica/OC.

\subsection{Dynamic mechanical properties}

Figure 8 compares the values of $\tan \delta$ at $-20,0$ and $60^{\circ} \mathrm{C}$ of the silica-filled NR, silica/OC-filled NR and silica/MMT-filled NR vulcanizates with varying loadings of modifying agent, taken from dynamic mechanical analysis in the temperature range from -80 to $80^{\circ} \mathrm{C}$, at a frequency of $10 \mathrm{~Hz}$ and $0.1 \%$ strain. The viscoelastic properties of a tread rubber are temperature dependence [62]. For laboratory scale verification of tire tread compound performance, $\tan \delta$ values obtained from dynamic mechanical analysis (DMA) are commonly used. The $\tan \delta$ values between 0 and $-40^{\circ} \mathrm{C}$ are used as indicators for wet and winter traction [63], whereas the $\tan \delta$ value at $60^{\circ} \mathrm{C}$ is indicative for rolling resistance $[64,65]$. A positive correlation between the rolling power loss captured by the rolling resistance testing machine with $\tan \delta$ values obtained from DMA or RPA had been recently confirmed for NR composites [65].
Figure 8 are indicative of ice and wet traction of tire tread rubber vulcanizates respectively, as evaluated on laboratory testing scale $[62,63]$. The $\tan \delta$ at $-20^{\circ} \mathrm{C}$ shows some improvement with the addition of modifying agent but has no clear trend. The silicafilled NR and silica/MMT-filled NR compounds show optimum $\tan \delta$ values at $-20^{\circ} \mathrm{C}$ at modifying agent content of $4.7 \mathrm{phr}$. However, there is no improvement of $\tan \delta$ at $0^{\circ} \mathrm{C}$. The silica/OC-filled NR shows an optimum $\tan \delta$ at $-20^{\circ} \mathrm{C}$ at $2.4 \mathrm{phr}$ of modifying agent, or at $5 \mathrm{phr}$ of OC loading, and then clearly drops at higher loadings of OC due to the reagglomeration of clay platelets as shown by the XRD results in Figure $7 \mathrm{~b}$, while the $\tan \delta$ at $0{ }^{\circ} \mathrm{C}$ shows comparable results as that of the pure silicafilled NR compound.

The $\tan \delta$ at $60^{\circ} \mathrm{C}$ is indicative of tire rolling resistance on a laboratory scale $[62,64,65]$ in which a lower $\tan \delta$ value at a temperature of $60^{\circ} \mathrm{C}$ indicates a reduced tire rolling resistance. These results obtained from both RPA and DMA analysis are shown in Figures $8 \mathrm{c}, 8 \mathrm{~d}$. The $\tan \delta$ at $60^{\circ} \mathrm{C}$ of silica-filled NR is generally reduced with increasing modifying agent, while the silica/MMT-filled NR compound shows an optimum point at $4.7 \mathrm{phr}$ of modifying agent content and the silica/OC-filled NR compound shows an optimum point at $2.4 \mathrm{phr}$ of modifying agent or at $5.0 \mathrm{phr}$ of OC loadings. With optimum loadings of modifying agent, lower $\tan \delta$ at $60^{\circ} \mathrm{C}$ can be obtained indicating the feasibility to reduce tire rolling resistance.

These combined results are summarized in the radar charts hereunder. Figure 9 shows the radar charts covering cure properties, Payne effects and mechanical properties of the compounds (Figure 9a), and tire performance lab-indicators (Figure $9 b$ ). The first chart is based on relative values versus the reference. While the chart concerning tire performance is based on index-values: the higher the better.

\section{Conclusions}

Overall, the addition of modifying agent to silica-reinforced rubber, either in the form of pre-modified MMT, or in combination with MMT or even added in pristine form to silica compounds, provides many benefits. Dependent on the properties of choice, different amounts of modifying agent need to be employed. The incorporation of modifying agent in a range of 0 to $9.5 \mathrm{phr}$ in silica-filled NR, silica/OCfilled NR and silica/MMT-filled NR compounds 

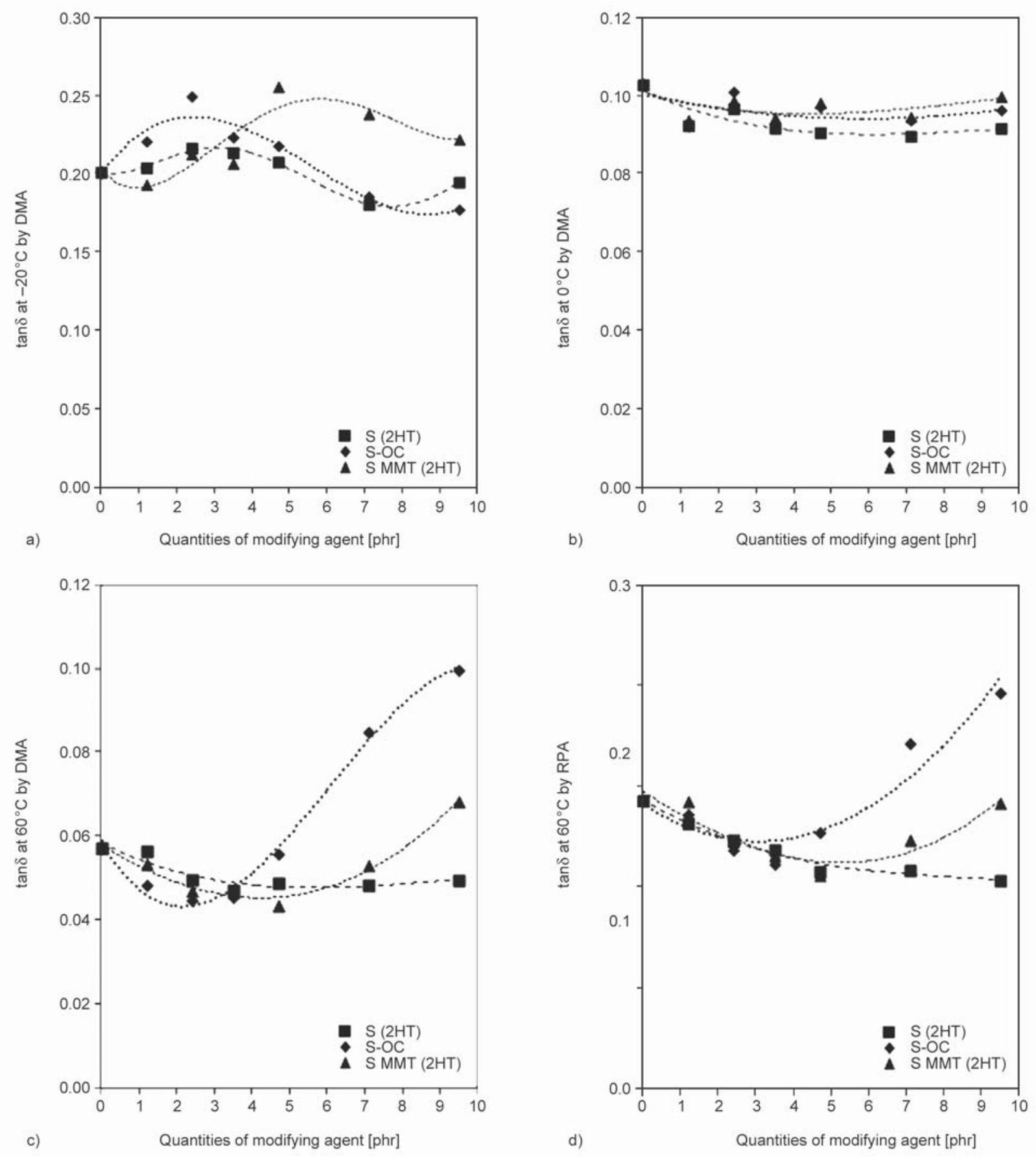

Figure 8. Tan $\delta$ at $-20^{\circ} \mathrm{C}$ (a), $\tan \delta$ at $0^{\circ} \mathrm{C}$ (b), $\tan \delta$ at $60^{\circ} \mathrm{C}$ from DMA (c), and $\tan \delta$ at $60^{\circ} \mathrm{C}$ from RPA (d) of silica-filled NR, silica/OC-filled NR and silica/MMT-filled NR compounds with varying loadings of modifying agent $2 \mathrm{HT}$.

results in a decreases of compound viscosity, Payne effects and scorch times. The optimum amount of modifying agent for silica-filled and silica/MMTfilled NR compounds are observed at $4.7 \mathrm{phr}$ as seen in the best balance of properties, i.e. lower Payne effects, higher tensile properties (tensile strength, $300 \%$ modulus, tear strength), higher DIN abrasion resistance index, higher apparent crosslink density, higher $\tan \delta$ at $-20^{\circ} \mathrm{C}$ and lower $\tan \delta$ at $60^{\circ} \mathrm{C}$. For silica/OC-filled, an optimum loading of modifying agent is observed at $2.4 \mathrm{phr}$ or at $5.0 \mathrm{phr}$ of OC where lower Payne effect, higher cure rate index, higher tensile properties and tear strength, higher DIN abrasion resistance index, higher apparent crosslink density, higher $\tan \delta$ at $-20^{\circ} \mathrm{C}$ and lower $\tan \delta$ at $60^{\circ} \mathrm{C}$ are obtained. The shorter scorch time, lower compound viscosities respectively particularly indicate better productivity by reduced cycle times for vulcanization and better processability. The lower $\tan \delta$ at $60^{\circ} \mathrm{C}$ is an indication of improved rolling resistance 


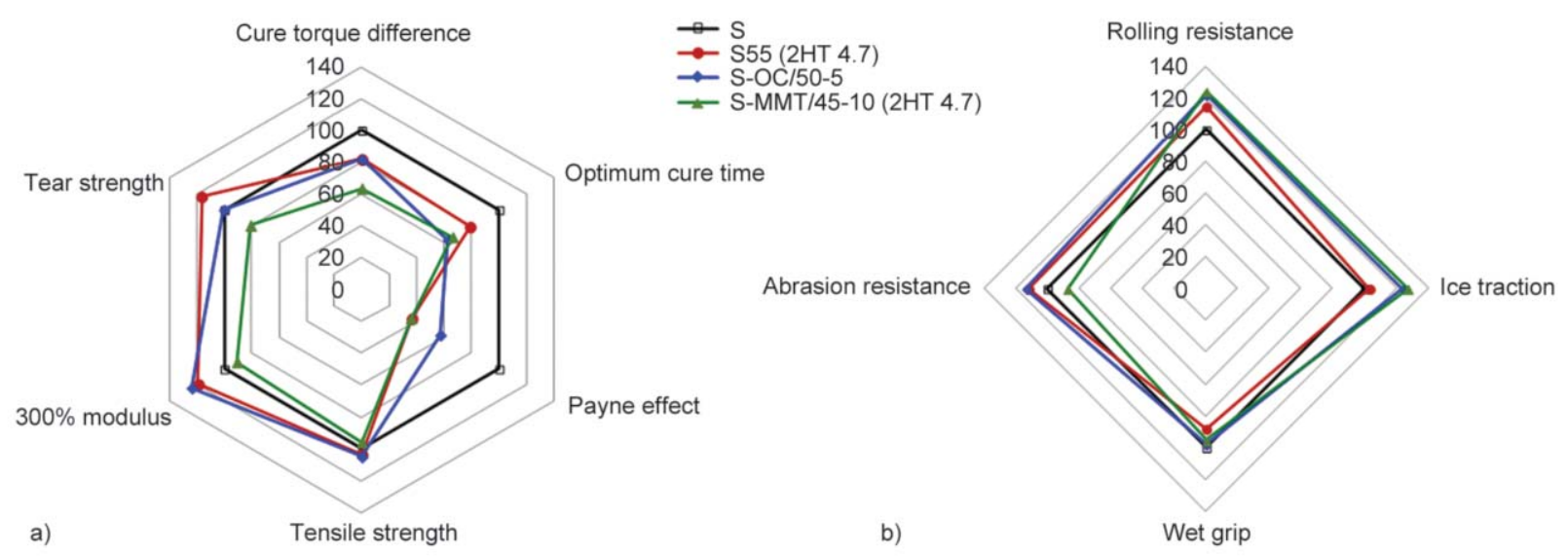

Figure 9. Radar charts comparing cure properties, Payne effect, tensile properties and tear strength (a), and key tire performances indicated by lab-indicators (b) of the NR compound filled with $55 \mathrm{phr}$ silica without organoclay as secondary filler: reference (S), the $55 \mathrm{phr}$ silica-filled NR compound with clay-modifier at an optimum amount of $4.7 \mathrm{phr}$ (S55 (2HT 4.7)), the NR compound filled with $50 \mathrm{phr}$ silica and $5 \mathrm{phr}$ organoclay as secondary filler (S-OC/50-5), and the NR compound filled with $45 \mathrm{phr}$ silica and $10 \mathrm{phr}$ unmodified nanoclay plus clay-modifier at $4.7 \mathrm{phr}$ (SMMT/45-10 (2HT 4.7)).

which can be achieved with tire treads based on such compounds. Also the higher $\tan \delta$ at $-20^{\circ} \mathrm{C}$ and DIN abrasion resistance index are indications for enhanced ice traction and wear resistance, which are favored for tire applications. So, irrespective in which form the modifying agent is added: included in OC or added separately, it has great potential to further improve NR/silica reinforced tire technology.

\section{Acknowledgements}

Authors wish to acknowledge the support from the Dutch Natural Rubber Foundation (Rubber Stichting, the Netherlands), Apollo Tyres Global R\&D B.V. (the Netherlands), and Prince of Songkla University (Thailand) Ph.D. Scholarship.

\section{References}

[1] Rodgers B., D’Cruz B.: Tire technology. in 'Rubber compounding: Chemistry and applications' (ed.: Rodgers B.) CRC Press, Boca Raton, 579-598 (2016). https://doi.org/10.1201/b18931

[2] Rauline R.: Rubber compound and tires based on such a compound. European Patent EP0501227A1, France (1992).

[3] Luginsland H. D., Niedermeier W.: New reinforcing materials for rising tire performance demands. Rubber World, 22, 34-45 (2003).

[4] Kaewsakul W., Sahakaro K., Dierkes W. K., Noordermeer J. W. M.: Optimization of rubber formulation for silica-reinforced natural rubber compounds. Rubber Chemistry and Technology, 86, 313-329 (2013).

https://doi.org/10.5254/rct.13.87970
[5] Wolff S.: Optimization of silane-silica OTR compounds. Part 1: Variations of mixing temperature and time during the modification of silica with bis-(3-triethoxisilylpropyl)-tetrasulfide. Rubber Chemistry and Technology, 55, 967-989 (1982). https://doi.org/10.5254/1.3535926

[6] Reuvekamp L., ten Brinke J. W., van Swaaij P. J., Noordermeer J. W. M.: Effects of mixing conditionsreaction of TESPT silane coupling agent during mixing with silica filler and tire rubber. Kautschuk Gummi Kunststoffe, 55, 41-47 (2002).

[7] Reuvekamp L. A. E. M., ten Brinke J. W., van Swaaij P. J., Noordermeer J. W. M.: Effects of time and temperature on the reaction of TESPT silane coupling agent during mixing with silica filler and tire rubber. Rubber Chemistry and Technology, 75, 187-198 (2002).

https://doi.org/10.5254/1.3544972

[8] Dierkes W. K., Noordermeer J. W. M., van de Pol C., Rinker M., Kelting K. U.: Increasing the silanisation efficiency of silica compounds: Upscaling. Kautschuk Gummi Kunststoffe, 56, 338-344 (2003).

[9] Kaewsakul W., Sahakaro K., Dierkes W. K., Noordermeer J. W. M.: Optimization of mixing conditions for silica-reinforced natural rubber tire tread compounds. Rubber Chemistry and Technology, 85, 277-294 (2012). https://doi.org/10.5254/rct.12.88935

[10] Sarkawi S. S., Dierkes W. K., Noordermeer J. W. M.: Reinforcement of natural rubber by precipitated silica: The influence of processing temperature. Rubber Chemistry and Technology, 87, 103-119 (2014).

https://doi.org/10.5254/rct.13.87925 
[11] Sattayanurak S., Noordermeer J. W. M., Sahakaro K., Kaewsakul W., Dierkes W. K., Blume A.: Silica-reinforced natural rubber: Synergistic effects by addition of small amounts of secondary fillers to silica-reinforced natural rubber tire tread compounds. Advances Materials Science and Engineering, 2019, 5891051/15891051/8 (2019).

https://doi.org/10.1155/2019/5891051

[12] Ghasemi I., Karrabi M., Mohammadi M., Azizi H.: Evaluating the effect of processing conditions and organoclay content on the properties of styrene-butadiene rubber/organoclay nanocomposites by response surface methodology. Express Polymer Letters, 4, 62-70 (2010). https://doi.org/10.3144/expresspolymlett.2010.11

[13] Sengloyluan K., Sahakaro K., Dierkes W. K., Noordermeer J. W. M.: Silica-reinforced tire tread compounds compatibilized by using epoxidized natural rubber. European Polymer Journal, 51, 69-79 (2014). https://doi.org/10.1016/j.eurpolymj.2013.12.010

[14] Saramolee P., Sahakaro K., Lopattananon N., Dierkes W. K., Noordermeer J. W. M.: Compatibilization of silica-filled natural rubber compounds by combined effects of functionalized low molecular weight rubber and silane. Journal of Rubber Research, 19, 28-42 (2016). https://doi.org/10.1177/0095244314568469

[15] Sengloyluan K., Sahakaro K., Dierkes W. K., Noordermeer J. W. M.: Silane grafted natural rubber and its compatibilization effect on silica-reinforced rubber tire compounds. Express Polymer Letters, 11, 10031022 (2017).

https://doi.org/10.3144/expresspolymlett.2017.95

[16] ten Brinke J. W., Debnath S. C., Reuvekamp L. A. E. M., Noordermeer J. W. M.: Mechanistic aspects of the role of coupling agents in silica-rubber composites. Composites Science and Technology, 63, 1165-1174 (2003). https://doi.org/10.1016/S0266-3538(03)00077-0

[17] Das A., Wang D-Y., Stöckelhuber K. W., Jurk R., Fritzsche J., Klüppel M., Heinrich G.: Rubber-clay nanocomposites: Some recent results. Advanced Rubber Composites, 239, 85-166 (2011).

https://doi.org/10.1007/12 201096

[18] Xu S. H., Gu J., Luo Y. F., Jia D. M.: Effects of partial replacement of silica with surface modified nanocrystalline cellulose on properties of natural rubber nanocomposites. Express Polymer Letters, 6, 14-25 (2012). https://doi.org/10.3144/expresspolymlett.2012.3

[19] Sadhu S. D., Maiti M., Bhowmick A. K.: Elastomerclay nanocomposites. in 'Current topics in elastomers research’ (ed.: Bhowmick A. K.) CRC Press, Boca Raton, 23-56 (2008). https://doi.org/10.1201/9781420007183

[20] Gatos K. G., Karger-Kocsis J.: Rubber/clay nanocomposites: Preparation, properties and applications. in 'Rubber nanocomposites: Preparation, properties, and applications' (eds.: Thomas S., Stephen R.) Wiley, Singapore, 169-195 (2010).

https://doi.org/10.1002/9780470823477
[21] Schön F., Gronski W.: Filler networking of silica and organoclay in rubber composites: Reinforcement and dynamic-mechanical properties. Kautschuk Gummi Kunststoffe, 56, 166-171 (2003).

[22] Lu Y-L., Ye F-Y., Mao L-X., Li Y., Zhang L-Q.: Microstructural evolution of rubber/clay nanocomposites with vulcanization process. Express Polymer Letters, 5, 777787 (2011).

https://doi.org/10.3144/expresspolymlett.2011.76

[23] Wolff S.: Chemical aspects of rubber reinforcement by fillers. Rubber Chemistry and Technology, 69, 325-346 (1996).

https://doi.org/10.5254/1.3538376

[24] Choi S-S.: Influence of polymer-filler interactions on retraction behaviors of natural rubber vulcanizates reinforced with silica and carbon black. Journal of Applied Polymer Science, 99, 691-696 (2006). https://doi.org/10.1002/app.22562

[25] Rattanasom N., Saowapark T., Deeprasertkul C.: Reinforcement of natural rubber with silica/carbon black hybrid filler. Polymer Testing, 26, 369-377 (2007). https://doi.org/10.1016/j.polymertesting.2006.12.003

[26] Feng W., Tang Z., Weng P., Guo B.: Correlation of filler networking with reinforcement and dynamic properties of SSBR/carbon black/silica composites. Rubber Chemistry and Technology, 88, 676-689 (2015). https://doi.org/10.5254/rct.15.84881

[27] Ulfah I. M., Fidyaningsih R., Rahayu S., Fitriani D. A., Saputra D. A., Winarto D. A., Wisojodharmo L. A.: Influence of carbon black and silica filler on the rheological and mechanical properties of natural rubber compound. Procedia Chemistry, 16, 258-264 (2015). https://doi.org/10.1016/j.proche.2015.12.053

[28] Senthilvel K., Vishvanathperumal S., Prabu B., Baruch J. L.: Studies on the morphology, cure characteristics and mechanical properties of acrylonitrile butadiene rubber with hybrid filler (carbon black/silica) composite. Polymers and Polymer Composites, 24, 473-480 (2016). https://doi.org/10.1177/096739111602400705

[29] Ogbebor O. J., Farid A. S., Okwu U. N.: Properties of silica/clay filled heavy-duty truck tire thread formulation. Journal of Applied Polymer Science, 94, 10241028 (2004). https://doi.org/10.1002/app.20921

[30] Nik Ismail N. I., Ansarifar A., Song M.: Effect of hybrid reinforcement based on precipitated silica and montmorillonite nanofillers on the mechanical properties of a silicone rubber. Polymer Engineering and Science, 54, 1909-1921 (2014). https://doi.org/10.1002/pen.23734

[31] Bao Z., Tao J., Flanigan C.: The combination of montmorillonite and silica in styrene-butadiene rubber/polybutadiene rubber tread compounds. Polymer Composites, 38, 918-926 (2017). https://doi.org/10.1002/pc.23653 
[32] Vijay V. R., Anitha A. M., Menon A. R. R.: Studies on blends of natural rubber and butadiene rubber containing silica - Organomodified kaolin hybrid filler systems. Polymer, 89, 135-142 (2016).

https://doi.org/10.1016/j.polymer.2016.02.037

[33] Kim W-S., Jang S. H., Kang Y. G., Han M. H., Hyun K., Kim W.: Morphology and dynamic mechanical properties of styrene-butadiene rubber/silica/organoclay nanocomposites manufactured by a latex method. Journal of Applied Polymer Science, 128, 2344-2349 (2013). https://doi.org/10.1002/app.38253

[34] Galimberti M., Cipolletti V., Cioppa S., Lostritto A., Conzatti L.: Reduction of filler networking in silica based elastomeric nanocomposites with exfoliated organo-montmorillonite. Applied Clay Science, 135, 168-175 (2017).

https://doi.org/10.1016/j.clay.2016.09.017

[35] Ismail H., Freakley P. K.: Determination of the modes of action of a cationic surfactant for property development in silica-filled natural rubber compounds. European Polymer Journal, 32, 411-416 (1996). https://doi.org/10.1016/0014-3057(95)00171-9

[36] Liu J., Wu C., Zhang P., Zhao S.: Effects of cyclohexylamine modified silica on the mechanical properties of filled natural rubber. Journal of Macromolecular Science Part B: Physics, 47, 689-700 (2008). https://doi.org/10.1080/00222340802118846

[37] Surya I., Ismail H., Azura A. R.: Alkanolamide as an accelerator, filler-dispersant and a plasticizer in silicafilled natural rubber compounds. Polymer Testing, 32, 1313-1321 (2013). https://doi.org/10.1016/j.polymertesting.2013.07.015

[38] Yang S. Y., Liu L., Jia Z. X., Fu W. W., Jia D. M., Luo Y. F.: Study on the structure-properties relationship of natural rubber $/ \mathrm{SiO}_{2}$ composites modified by a novel multi-functional rubber agent. Express Polymer Letters, 8, 425-435 (2014).

https://doi.org/10.3144/expresspolymlett.2014.46

[39] Sookyung U., Nakason C., Vennemann N., Thaijaroen $\mathrm{W}$.: Influence concentration of modifying agent on properties of natural rubber/organoclay nanocomposites. Polymer Testing, 54, 223-232 (2016). https://doi.org/10.1016/j.polymertesting.2016.07.009

[40] Kim W-S., Lee D-H., Kim I-J., Son M-J., Kim W., Cho S-G.: SBR/organoclay nanocomposites for the application on tire tread compounds. Macromolecular Research, 17, 776-784 (2009).

https://doi.org/10.1007/BF03218614

[41] Guy L., Daudey S., Cochet P., Bomal Y.: New insights in the dynamic properties of precipitated silica filled rubber using a new high surface silica. Kautschuk Gummi Kunststoffe, 62, 383-391 (2009).

[42] Choi S-S., Lee H-M., Ko J-E., Kim M-C.: Recovery behaviors of silica-reinforced SBR vulcanizates using circular deformation test. Industrial Engineering and Chemistry, 13, 1169-1173 (2007).

https://www.cheric.org/PDF/JIEC/IE13/IE13-7-1169.pdf
[43] Flory P. J., Rehner J. J.: Statistical mechanics of crosslinked polymer networks II. Swelling. The Journal of Chemical Physics, 11, 521-526 (1943).

https://doi.org/10.1063/1.1723792

[44] Payne A. R.: Effect of dispersion on dynamic properties of filler-loaded rubbers. Rubber Chemistry and Technology, 39, 365-374 (1996).

https://doi.org/10.5254/1.3544848

[45] Blume A., Thibault-Starzyk F.: Deciphering the silica/ silane reaction mechanism for the development of a new generation of low rolling resistance tires: Part 1Characterization by in situ IR spectroscopy. Rubber Fibres Plastics International, 12, 152-157 (2017).

[46] Blume A., Thibault-Starzyk F.: Deciphering the silica/ silane reaction mechanism for the development of a new generation of low rolling resistance tires: Part 2Transfer of results from model examinations into practice. Rubber Fibres Plastics International, 12, 236-241 (2017).

[47] Wolff S., Wang M-J., Tan E-H.: Filler-elastomer interactions. Part VII. Study on bound rubber. Rubber Chemistry and Technology, 66, 163-177 (1993).

https://doi.org/10.5254/1.3538304

[48] Galimberti M., Coombs M., Cipolletti V., Giannini L., Conzattl L.: The origin of synergism between an organoclay and carbon black. Applied Clay Science, 83-84, 449-456 (2013)

https://doi.org/10.1016/j.clay.2013.06.035

[49] Choi S-S.: Influence of the silica content on rheological behaviour and cure characteristics of silica-filled styrene-butadiene rubber compounds. Polymer International, 50, 524-530 (2001).

https://doi.org/10.1002/pi.660

[50] Carli L. N., Roncato C. R., Zanchet A., Mauler R. S., Giovanela M., Brandalise R. N., Cresp J. S.: Characterization of natural rubber nanocomposites filled with organoclay as a substitute for silica obtained by the conventional two-roll mill method. Applied Clay Science, 52, 56-61 (2011). https://doi.org/10.1016/j.clay.2011.01.029

[51] López-Manchado M. A., Herrero B., Arroyo M.: Organoclay-natural rubber nanocomposites synthesized by mechanical and solution mixing methods. Polymer International, 53, 1766-1772 (2004).

https://doi.org/10.1002/pi.1573

[52] Teh P. L., Mohd Ishak Z. A., Hashim A. S., KargerKocsis J., Ishiaku U. S.: On the potential of organoclay with respect to conventional fillers (carbon black, silica) for epoxidized natural rubber compatibilized natural rubber vulcanizates. Journal of Applied Polymer Science, 94, 2438-2445 (2004).

https://doi.org/10.1002/app.21188

[53] Choi D., Kader M. A., Cho B-K., Huh Y-I., Nah C.: Vulcanization kinetics of nitrile rubber/layered clay nanocomposites. Journal of Applied Polymer Science, 98, 1688-1696 (2005).

https://doi.org/10.1002/app.22341 
[54] Avalos F., Ortiz J. C., Zitzumbo R., López-Manchado M. A., Verdejo R., Arroyo M.: Effect of montmorillonite intercalant structure on the cure parameters of natural rubber. European Polymer Journal, 44, 3108-3115 (2008).

https://doi.org/10.1016/j.eurpolymj.2008.07.020

[55] Sookyung U., Nakason C., Thaijaroen W., Vennemann N.: Influence of modifying agents of organoclay on properties of nanocomposites based on natural rubber. Polymer Testing, 33, 48-56 (2014).

https://doi.org/10.1016/j.polymertesting.2013.11.006

[56] Fathurrohmanm M. I., Soegijono B., Budianto E., Rohman S., Ramadhan A.: The effect of organoclay on curing characteristic, mechanical properties, swelling and morphology of natural rubber/organoclay nanocomposites. Macromolecular Symposia, 353, 62-69 (2015). https://doi.org/10.1002/masy.201550308

[57] George S. C., Rajan R., Aprem A. S., Thomas S., Kim S. S.: The fabrication and properties of natural rubberclay nanocomposites. Polymer Testing, 51, 165-173 (2016).

https://doi.org/10.1016/j.polymertesting.2016.03.010

[58] Fathurrohman M. I., Rugmai S., Hayeemasae N., Sahakaro K.: Dispersion and properties of natural rubber-montmorillonite nanocomposites fabricated by novel in situ organomodified and latex compounding method. Polymer Engineering and Science, 59, 1830-1839 (2019). https://doi.org/10.1002/pen.25183

[59] Sattayanurak S.: Silica-reinforced natural rubber: Shifting tire performance by hybridization with secondary fillers and polymers. $\mathrm{PhD}$ thesis, University of Twente, the Netherlands (2018).

https://doi.org/10.3990/1.9789036549271
[60] Galimberti M., Senatore S., Lostritto A., Giannini L., Conzatti L., Costa G., Guerra G.: Reinforcement of diene elastomers by organically modified layered silicates. E-Polymers, 9, 057/1-057/16 (2009). https://doi.org/10.1515/epoly.2009.9.1.700

[61] Galimberti M., Coombs M., Cipolletti V., Riccio P., Riccó T., Pandini S., Conzatti L.: Enhancement of mechanical reinforcement due to hybrid filler networking promoted by an organoclay in hydrocarbon-based nanocomposites. Applied Clay Science, 65-66, 57-66 (2012).

https://doi.org/10.1016/j.clay.2012.04.019

[62] Nordsiek K. H.: The 'integral rubber' concept - An approach to an ideal tire tread rubber. Kautschuk Gummi Kunststoffe, 38, 178-185 (1985).

[63] Waddell W. H., Kuhr J. H., Poulter R. R.: Evaluation of isobutylene-based elastomers in a model winter tire tread. Rubber Chemistry and Technology, 76, 348-364 (2003).

https://doi.org/10.5254/1.3547748

[64] Vleugels N., Pille-Wolf W., Dierkes W. K., Noordermeer J. W. M.: Understanding the influence of oligomeric resins on traction and rolling resistance of silicareinforced tire treads. Rubber Chemistry and Technology, 88, 65-79 (2015).

https://doi.org/10.5254/rct.14.86947

[65] Xu T-W., Jia Z-X., Chen Y-J., Jia D-M., Wang Y-Q.: Correlations between the hysteresis parameters determining the rolling resistance in rubber composites. International Polymer Processing, 35, 16-25 (2020). https://doi.org/10.3139/217.3751 